Supporting Information

\title{
Bifunctional Nitrone-Conjugated Secondary Metabolite Targeting the Ribosome
}

Emilianne M. Limbrick 1,\#,\#, Michael Graf ${ }^{2, \#, ~ D a g m a r a ~ K . ~ D e r e w a c z ', ~ F a b i a n ~ N g u y e n ², ~ J e f f r e y ~ M . ~}$ Spraggins ${ }^{1,3,4}$, Maximiliane Wieland ${ }^{2}$, Audrey E. Ynigez-Gutierrez ${ }^{1}$, Benjamin J. Reisman ${ }^{1}$, Boris Zinshteyn $^{5}$, Kathryn M. McCulloch ${ }^{6, \S}$, T. M. Iverson ${ }^{3,6,9}$, Rachel Green ${ }^{5,7}$, Daniel N. Wilson ${ }^{2^{\star}}$ and Brian 0 . Bachmann ${ }^{1,3,6,8^{*}}$

${ }^{1}$ Department of Chemistry, Vanderbilt University, Nashville, TN 37235, USA

${ }^{2}$ Gene Center and Department of Biochemistry, University of Munich, 81377 Munich, Germany

${ }^{3}$ Department of Biochemistry, Vanderbilt University School of Medicine, Nashville, TN 37205, USA

${ }^{4}$ Mass Spectrometry Research Center, Vanderbilt University School of Medicine, Nashville, TN 37232, USA

${ }^{5}$ Department of Molecular Biology and Genetics, Johns Hopkins University. Baltimore, MD 21205, USA

${ }^{6}$ Department of Pharmacology, Vanderbilt University, Nashville, TN 37232

${ }^{7}$ Howard Hughes Medical Institute, Johns Hopkins University School of Medicine, Baltimore, MD 21205, USA.

${ }^{8}$ Vanderbilt Institute of Chemical Biology

${ }^{9}$ Vanderbilt Center for Structural Biology

§Present address: Department of Chemistry and Biochemistry, Cal Poly Pomona, Pomona, CA 91768

¥Present address: Department of Chemistry, Mercer University, Macon, GA 31207

\# These authors contributed equally to this work

"Correspondence: brian.bachmann@vanderbilt.edu and daniel.wilson@chemie.uni-hamburg.de

\section{$\underline{\text { Table of Contents }}$}

\section{Supplementary Methods}

\section{Supplementary Figures}

Figure S1. A. Everninomicin gene cluster and B. genetic complementation plasmid map.

Figure S2. Southern hybridization data.

Figure S3. Evn N mass spectrometric fragmentation data.

Figure S4. Evn M mass spectrometric fragmentation data.

Figure S5. ${ }^{1} \mathrm{H}$ proton NMR of Evn $\mathrm{N}$ in $\mathrm{CD}_{4} \mathrm{OD}$.

Figure S6. ${ }^{13} \mathrm{C}$ carbon NMR of Evn $\mathrm{N}$ in $\mathrm{CD}_{4} \mathrm{OD}$.

Figure S7. COSY NMR of Evn N in $\mathrm{CD}_{4} \mathrm{OD}$.

Figure S8. HSQC NMR of Evn $\mathrm{N}$ in $\mathrm{CD}_{4} \mathrm{OD}$.

Figure S9. HMBC NMR of Evn $\mathrm{N}$ in $\mathrm{CD}_{4} \mathrm{OD}$.

Figure S10. TOCSY NMR of Evn N in $\mathrm{CD}_{4} \mathrm{OD}$.

Figure S11. NOESY NMR of Evn N in $\mathrm{CD}_{4} \mathrm{OD}$.

Figure S12. ${ }^{1} \mathrm{H}$ proton NMR of Evn $\mathrm{O}$ in $\mathrm{CD}_{4} \mathrm{OD}$.

Figure S13. COSY NMR of Evn O in $\mathrm{CD}_{4} \mathrm{OD}$.

Figure S14. HSQC NMR of Evn $\mathrm{O}$ in $\mathrm{CD}_{4} \mathrm{OD}$.

Figure S15. HMBC NMR of Evn $\mathrm{O}$ in $\mathrm{CD}_{4} \mathrm{OD}$.

Figure S16. TOCSY NMR of Evn O in $\mathrm{CD}_{4} \mathrm{OD}$.

Figure S17. NOESY NMR of Evn $\mathrm{O}$ in $\mathrm{CD}_{4} \mathrm{OD}$.

Figure S18. ${ }^{1} \mathrm{H}$ proton NMR of Evn $\mathrm{P}$ in $\mathrm{CD}_{4} \mathrm{OD}$.

Figure S19. COSY NMR of Evn $P$ in $\mathrm{CD}_{4} \mathrm{OD}$.

Figure S20. HSQC NMR of Evn $P$ in $C D_{4} O D$.

Figure S21. HMBC NMR of Evn $P$ in $C^{2} D_{4} O D$.

Figure S22. Degradation of Evn P.

Figure S23. Activity of everninomicin analogs.

Figure S24. DMS-Map-Seq. 
Figure S25. Biosynthetic gene cluster for rosarimicin in M. carbonacea var. aurantiaca.

Figure S26. HPLC/MS analysis of a crude extract of $M$. carbonacea var. aurantiaca under conditions for production of Evn P.

\section{Supplementary Tables}

Table S1. Masses of everninomicins.

Table S2. Evn N NMR data.

Table S3. Evn O NMR data.

Table S4. Evn P NMR data.

Table S5. Strains and plasmids used in this study.

Table S6. Primers used in this study.

Table S7 Summary of genome assemblies for M. Carbonacea strains. 


\section{Methods}

\section{General Experimental Procedures}

Bacterial culture conditions: $E$. coli strains were grown in LB broth. M. carbonacea var. aurantiaca NRRL 2997 and replacement mutants were grown on TSB (Tryptone Soy Broth) agar and in TSB liquid. Intergeneric conjugations were performed on solid AS1 media $(0.1 \%$ yeast extract, $0.5 \%$ soluble starch, $0.02 \%$ L-alanine, $0.02 \%$ L-arginine, $0.05 \%$ L-asparagine, $0.25 \% \mathrm{NaCl}, 1 \% \mathrm{Na}_{2} \mathrm{SO}_{4}, 2 \%$ agarose at pH 7.5 , supplemented with $10 \mathrm{mM} \mathrm{MgCl}$ ). Apramycin $(50 \mu \mathrm{g} / \mathrm{ml})$, nalidixic acid $(25 \mu \mathrm{g} / \mathrm{ml})$, chloramphenicol (30 $\mu \mathrm{g} / \mathrm{ml})$, and kanamycin $(50 \mu \mathrm{g} / \mathrm{ml})$ were used when required for selection as described below. Specific strains and plasmids used in this study can be found in tables S5-6.

\section{Generation of gene replacements in E. coli}

The genes evdN1 were individually deleted on cosmid using a PCR-targeting gene replacement strategy described by Gust et al. 1-2 Lambda-Red competent cells were prepared by inoculating $1 \%$ of a fresh overnight culture of $E$. coli BW25113/plJ790 containing EveD cosmids into $10 \mathrm{~mL}$ LB medium containing $20 \mathrm{mM} \mathrm{MgSO}_{4}, 10 \mathrm{mM} \mathrm{L}$-arabinose, and kanamycin. The culture was grown with shaking at $30{ }^{\circ} \mathrm{C}$ to an $\mathrm{OD}_{600}$ of 0.6 . Cells were recovered by centrifugation at $3000 \mathrm{xg}$ for 10 minutes at $4{ }^{\circ} \mathrm{C}$ and the pellet was washed three times with $10 \mathrm{~mL}$ ice-cold $10 \%$ glycerol, resuspended in $100 \mu \mathrm{L}$ ice-cold $10 \%$ glycerol, and kept on ice.

The gene replacement cassette containing the apramycin resistance marker (aac(3)IV), oriT, and FRT regions was amplified by PCR using the primers listed in table S6. The $1.4 \mathrm{~kb}$ PCR products were then directly transformed via electroporation into the arabinose-induced strain BW25113/plJ790 containing the cosmid, in which lambda-Red mediated homologous recombination enabled replacement of the gene of interest. Transformed E. coli were plated on LB agar containing apramycin and incubated overnight at 37 ${ }^{\circ} \mathrm{C}$ to promote loss of the temperature sensitive plasmid plJ790. Colonies from these plates were inoculated into liquid LB containing apramycin and grown with shaking overnight at $37^{\circ} \mathrm{C}$. The gene replacements were confirmed by PCR using primers DelUp and DelDn and by sequencing. The resultant cosmids were transformed via electroporation into the non-methylating E. coli strain ET12567 containing plasmid pUZ8002, which contains the genes necessary for conjugal transfer of the cosmid. The gene replacements in E. coli were maintained at $37{ }^{\circ} \mathrm{C}$ in liquid LB medium containing kanamycin, apramycin, and chloramphenicol.

\section{Generation of gene replacements in $M$. carbonacea var. aurantiaca}

M. carbonacea var. aurantiaca was grown on TSB agar for 7 days at $30^{\circ} \mathrm{C}$. Conjugal acceptor mycelia were prepared by inoculating a loop of mycelia into $10 \mathrm{~mL}$ of TSB medium in a $50 \mathrm{~mL}$ Falcon tube and incubating with shaking at $30{ }^{\circ} \mathrm{C}$ for 5 days. The culture was then centrifuged at $3000 \mathrm{xg}$ for 10 minutes and the pellet resuspended in $2 \mathrm{~mL}$ fresh TSB. $150 \mu \mathrm{L}$ aliquots were transferred into sterile $1.5 \mathrm{~mL}$ Eppendorf tubes and homogenized using a sterile plastic cell homogenizer. Donor $E$. coli ET12567/pUZ8002 cells containing the gene replacement were prepared by inoculating $1 \%$ of a freshly prepared overnight LB culture into $10 \mathrm{~mL}$ LB medium in a $50 \mathrm{~mL}$ Falcon tube containing apramycin and kanamycin and grown to an $\mathrm{OD}_{600}$ of 0.4 at $37^{\circ} \mathrm{C}$ with shaking. The culture was centrifuged at $3000 \times \mathrm{g}$ for 10 minutes, and the pellet was washed three times with $10 \mathrm{~mL}$ fresh LB. After the final wash, the pellet was resuspended in $150 \mu \mathrm{L}$ LB. Next, $50 \mu \mathrm{L}$ of donor $E$. coli was added to $150 \mu \mathrm{L}$ of recipient $M$. carbonacea. Prior to plating, a sterile $0.4 \mu \mathrm{m}$ membrane was attached to a sterile plastic washer using silicon glue. After drying, each membrane-washer apparatus was placed on an AS1 plate. The mixture of bacteria was plated on top of the membrane-washer setup. After 16 hours of incubation at $30^{\circ} \mathrm{C}$, apramycin $(50 \mu \mathrm{g} / \mathrm{mL})$ was added to the bacteria mixture on top of the assembly to select for apramycin-resistant exconjugants. After 7-9 days of incubation at $30^{\circ} \mathrm{C}$, membranes were removed and colonies were streaked onto TSB plates containing apramycin. Double-crossover mutants were identified by testing for kanamycin sensitivity and PCR amplification of kanamycin and apramycin resistance genes using primers AprUp and AprDn for amplifying the apramycin resistance gene and NeoUp and NeoDn for amplifying the kanamycin resistance 
gene. Double-crossover mutants in $M$. carbonacea were confirmed by Southern hybridization. Gene specific probes were designed upstream of the genes of interest. The evdN1 probe (700 bp) was amplified using primers EvdN1-Southern-For and EvdN1-Southern-Rev. An 884 bp probe specific to the apramycin resistance gene was also designed and amplified using primers Apr-Southern-For and Apr Southern-Rev. All probes were labeled with digoxigenin using the DIG High Prime DNA Labeling and Detection Starter Kit II (Roche Diagnostics $\mathrm{GmbH}$, Mannheim Germany). Hybridization and detection were also performed using the DIG Starter Kit.

\section{Production of everninomicins}

Seed cultures were generated by inoculating a loop of mycelia from a fresh TSB plate into $100 \mathrm{~mL}$ of 2997 germination medium ( $0.3 \%$ beef extract, $0.5 \%$ tryptose, $0.1 \%$ dextrose, $2.4 \%$ soluble starch, $0.5 \%$ yeast extract, $0.1 \%$ calcium carbonate, and for mutants $50 \mu \mathrm{g} / \mathrm{mL}$ apramycin) and grown with shaking for 5 days at $30{ }^{\circ} \mathrm{C}$ in a $500 \mathrm{~mL}$ Erlenmeyer flask. For production of everninomicins, $25 \mathrm{~mL}$ of the seed culture was added to $500 \mathrm{~mL}$ production medium $(0.5 \%$ yeast extract, $0.1 \%$ corn steep solids, $0.1 \%$ calcium carbonate, $3 \%$ glucose) in a $2 \mathrm{~L}$ baffled Fernbach flask and grown with shaking at $30{ }^{\circ} \mathrm{C}$ for 10 days. Diaion HP-20 resin (100 $\mathrm{mL}$, previously pre-equilibrated with methanol and washed with water) was added to the fermentation cultures and incubated for 60 minutes with shaking. The resin and mycelia were collected by centrifugation at $3000 \mathrm{x}$ g. The pellets were extracted first with $250 \mathrm{~mL}$ methanol for 60 minutes then 250 $\mathrm{mL}$ acetone for 60 minutes. The methanol and acetone fractions were combined and evaporated to dryness by rotary evaporation. The resulting crude oily extract was filtered through a fritted glass funnel containing silica gel $(9 \times 2 \mathrm{~cm})$ via vacuum filtration, eluted with methanol and concentrated to dryness. Extracts were resuspended at a final concentration of $200 \mathrm{mg} / \mathrm{mL}$ in HPLC grade methanol prior to analysis by LC/MS. Evn H, the D-ring des-C-3-methyl analog of Evn D was isolated from a methyltransferase variant in a parallel study. ${ }^{3}$

\section{HPLC/MS of Crude Extracts}

The extracts were analyzed in both negative and positive ion modes using a TSQ Quantum Access Max triple stage quadrupole mass spectrometer (Thermo Scientific, Waltham, MA) equipped with a HESI electrospray ionization source. Injections of $20 \mu \mathrm{l}$ were separated on Accucore $\mathrm{C}_{18}$ column $(150 \times 4.6 \mathrm{~mm}$, Thermo Scientific, Waltham, MA) using a Finnigan Surveyor LC Pump Plus (Thermo Scientific, Waltham, MA). Mobile phases were: (A) $95 \%$ water $/ 5 \%$ acetonitrile with $10 \mathrm{mM}$ ammonium acetate and (B) $5 \%$ water/95\% acetonitrile with $10 \mathrm{mM}$ ammonium acetate. Gradient conditions were: $0-1 \mathrm{~min}, 100 \% \mathrm{~A} ; 1-20$ min, linear gradient to $100 \%$ B; $20-26$ min, $100 \%$ B; $26-7$ min, linear gradient to $100 \%$ A; $27-30$ min, $100 \%$ A. The flow rate was maintained at $1 \mathrm{ml} / \mathrm{min}$ with $15 \mu \mathrm{l}$ sent to an Accela PDA detector (Thermo Scientific) and $5 \mu \mathrm{l}$ subjected to mass spectral analysis. Nitrogen was used for both the auxiliary and sheath gas, set to $10 \mathrm{psi}$ and $54 \mathrm{psi}$ respectively. For positive ion mode: capillary temperature $275^{\circ} \mathrm{C}$; spray voltage 4.5 $\mathrm{kV}$; capillary offset $35 \mathrm{~V}$; tube lens voltage $133 \mathrm{~V}$; skimmer offset $5 \mathrm{~V}$. For negative ion mode: capillary temperature $275^{\circ} \mathrm{C}$; spray voltage $3.0 \mathrm{kV}$; capillary offset $-35 \mathrm{~V}$; tube lens voltage $-132 \mathrm{~V}$; skimmer offset $5 \mathrm{~V}$. For fragmentation studies, a collision energy of $30 \mathrm{~V}$ was used.

\section{Isolation of Everninomicin Analogs}

The first dimension of separation for crude extracts was size-exclusion chromatography using a Sephadex $\mathrm{LH} 20$ column in methanol. Fractions were analyzed by LC/MS, and the fractions containing everninomicins were combined and separated by RP-HPLC using a linear gradient. Mobile phases were: (A) $99 \%$ water $/ 1 \%$ acetonitrile with $10 \mathrm{mM}$ ammonium acetate, $\mathrm{pH}=8$ and (B) $5 \%$ water $/ 95 \%$ acetonitrile with $10 \mathrm{mM}$ ammonium acetate, $\mathrm{pH}=8$. Evn $\mathrm{O}$ and $\mathrm{P}$, identified in the $\Delta$ evd01::aac(3)IV GC strain, were also determined to be present in the $\Delta$ evdM2::aac(3)IV strain, generated in a previous study at higher concentrations than in the $\Delta$ evd01::aac(3)IV GC strain, presumably due to polar effect in the operon it initiates (see Figure S1A). Therefore, $\Delta$ evdM2::aac(3)IV was selected to be used for isolation for NMR structure determination of Evn $\mathrm{O}$ and EnvP, 


\section{Fragmentation Analysis of Everninomicins}

Structural identification was performed using a 15T solariX FT-ICR mass spectrometer (Bruker Daltonics, Billerica, MA, USA) to provide both accurate mass measurements and tandem mass spectrometry fragmentation patterns. ${ }^{4}$ External mass calibration was performed prior to analysis (ESI-L Tuning Mix, Agilent Technologies, Santa Clara, CA). Evn H was detected as [M+Na] $]^{+}(\mathrm{m} / \mathrm{z} 1546.4919,-1.01 \mathrm{ppm})$ by electrospray ionization respectively. This ion was isolated in the source region of the instrument (quadrupole isolation window: $1.5 \mathrm{Da}$ ), accumulated in the collisional hexapole $(10-40 \mathrm{~s})$, and fragmented by sustained off-resonance irradiation collision induced dissociation (SORI-CID) in the ICR cell using pulsed argon (pulse length: $0.25 \mathrm{~s}$, frequency offset: $500 \mathrm{~Hz}$, SORI Power: 2.8-3.1\%). ${ }^{5}$

The structure of Evn M was confirmed using the TSQ Quantum Access Max triple stage quadrupole mass spectrometer and parameters described above. Collision energies of $20 \mathrm{~V}-40 \mathrm{~V}$ with a skimmer offset of $5 \mathrm{~V}$ were employed in positive mode to fragment Evn M.

\section{Genetic Complementation of Replacement Strains}

For complementation of $\Delta e v d N 1:: a a c(3) I V$, the evdN1 gene was amplified by PCR using the primers listed in table S6. The PCR product was subsequently cloned into the Ndel and EcoRV sites of pSET152ermE. For complementation of $\Delta$ evdO1::aac(3)IV, an additional plasmid was ordered from Mutagenex that included evdO1 cloned into the EcoRV and EcoRI sites of pSET152ermE to generate pSET152ermE+evdO1. Each of the complementation plasmids above was transformed into the conjugal E. coli strain ET12567/pUZ8002. Conjugation between the donor E. coli and recipient $M$. carbonacea was performed in the same manner as listed above, except that apramycin and hygromycin were added after 16 hours of incubation to select for mutants that contained the gene replacement as well as the genetic complementation plasmid. Crude extracts of the complemented strains were prepared and analyzed by $\mathrm{HPLC} / \mathrm{MS}$ as described.

\section{Genomic Sequencing of everninomicin producing organisms}

Library Preparation: Genomic DNA from M. carbonacea var. auriantiaca (ATTC 27115, NRRL 2997) and M. carbonacea var. africans (ATTC 39149, NRRL 15099) was prepared by CTAB extraction ${ }^{6}$ and dried genomic DNA was dissolved for $>4 \mathrm{~h}$ in $10 \mathrm{mM}$ Tris-Cl buffer, $\mathrm{pH}=8.5$. The nanopore sequencing library was prepared using the Oxford Nanopore Technologies Inc. protocol for barcoding kits (cat. \# SQK-LSK109 and EXP-NBD104). Sequencing was carried out on a MinION R9.4.1 flow cell. The Illumina dye sequencing library was prepared using the Nextera Flex library preparation kit and paired-end sequenced on a NovaSeq6000 sequencer (PE 150) (Illumina, Inc.) in the Vanderbilt Technologies for Advanced Genomics core facility (VANTAGE). Bioinformatics: Raw nanopore reads were base-called and demultiplexed via the guppy 3.6.1 algorithm using the high accuracy model, adapters removed using porechop 0.2.4, [github.com/rrwick/Porechop] and filtered to 60-fold coverage using filtlong 0.2.0. (github.com/rrwick/Filtlong) Illumina reads were downsampled to 100x coverage using seqtk. (https://github.com/lh3/seqtk) The draft assembly was constructed using the nanopore reads via the Flye assembler (version 2.7 ${ }^{7}$ and polished with racon and medaka 1.0.3. (https://github.com/nanoporetech/medaka) The Illumina reads were then used to further improve the quality of the nanopore assembly using pilon ${ }^{8}$ via the unicycler ${ }^{9}$ polishing module. Annotations were generated using the PGAP by NCBI after submission to genbank. Biosynthetic gene clusters were annotated using antiSMASH version $5.0^{10}$ using the online web portal with manual adjustment of the evd and ros gene clusters based on the patent literature. Genome quality was evaluated using BUSCO ${ }^{11}$ and QUAST ${ }^{12}$. See Table S7 for summary of genome assemblies for $M$. carbonacea var. auriantiaca (GenBank accession CP058322) and M. carbonacea var. africans (GenBank accession CP058905, CP058906). 


\section{Bioactivity Testing}

The antibacterial activity of the everninomicins was determined by the broth microdilution assay according to NCCLS guidelines using Staphylococcus aureus subsp. aureus Rosenbach (ATCC 6538P) as the test organism. ${ }^{13}$

\section{Degradation of everninomicin-rosamicin conjugate}

Purified Evn $\mathrm{P}$ (concentration of $0.2 \mathrm{mg} / \mathrm{mL}$ in $90 \%$ water $/ 10 \% \mathrm{DMSO}$ ) was incubated at $30^{\circ} \mathrm{C}$ with shaking for 48 hours. Aliquots were taken at each designated time point and subjected to LC/MS analysis.

\section{Erythromycin competition assays}

Binding of Evn, Rosa, Evn $\mathrm{P}$ and erythromycin (ERY) to an empty E. coli $70 S$ ribosome was monitored using a competition assay with radiolabelled $\left[{ }^{14} \mathrm{C}\right]$-erythromycin, as described before. ${ }^{14-15}$ Briefly, $20 \mu \mathrm{L}$ reactions containing 5 pmoles of ribosomes in buffer $\mathrm{C}\left(10 \mathrm{mM} \mathrm{HEPES}-\mathrm{KOH} \mathrm{pH} 7.8,30 \mathrm{mM}, \mathrm{MgCl}_{2}, 150\right.$ $\mathrm{mM} \mathrm{NH}{ }_{4} \mathrm{Cl}$, and $6 \mathrm{mM} \beta$-mercaptoethanol) were pre-incubated with $1.25 \mu \mathrm{M}$ of $\left[{ }^{14} \mathrm{C}\right]$-erythromycin $(170$ $\mathrm{dpm} / \mathrm{pmol}$ ), which resulted in binding of ERY to $60 \%$ of the ribosomes according to the saturation curve (data not shown). To assess binding of other antibiotics, ribosomal complexes with $\left[{ }^{14} \mathrm{C}\right]$-erythromycin were incubated with increasing amounts of either Evn H, Rosa, Evn P or Ery for 2 hrs at room temperature. Reactions were then passed through an HA-type $0.45 \mathrm{~mm}$ pore size nitrocellulose filter (Merck Millipore). Filters were washed three times with buffer $C$ and then scintillation counted in the presence of Filtersafe scintillant (Zinsser Analytic).

\section{Chemical protection assays using DMS-MaPseq}

Crude E. coli $70 S$ ribosomes were prepared exactly as previously described. ${ }^{16} \mathrm{DMS}$ probing was performed on 25 picomoles of $E$. coli ribosomes in a total volume of $25 \mu$ containing $30 \mathrm{mM} \mathrm{HEPES}, 7 \mathrm{mM}$ magnesium acetate, $100 \mathrm{mM}$ potassium chloride, $2 \mathrm{mM}$ DTT, and 10 or $100 \mu \mathrm{M}$ of drug, or an equal volume of DMSO. Probing was initiated by addition of $1 \mu \mathrm{l}$ of $2.5 \mathrm{M}$ dimethyl sulfate (sigma D186309, use within 6 months) diluted in ethanol, and incubation at $37^{\circ} \mathrm{C}$ for 5 minutes. Reactions were quenched by addition of $475 \mu \mathrm{l}$ of quench buffer (30\% 2-mercaptoethanol, $0.3 \mathrm{M}$ sodium acetate). RNA was purified and sequencing libraries constructed exactly as previously described. ${ }^{17}$ Libraries were sequenced on an Illumina HiSeq 2500 in 100nt single-end mode at the Johns Hopkins Genetic Resources Core Facility. Data analysis was adapted ${ }^{17}$ to accommodate E. coli rRNA sequences. Adaptor-trimmed reads were processed with the Shape-Mapper package ${ }^{18}$ to further trim the reads based on quality, and to count mismatches relative to a consensus MRE600 rDNA sequence. ${ }^{19}$ Several rRNA nucleotides have in vivo modifications or heterogeneity between rRNA copies (16S rRNA nucleotides 1207, 1498, 1518, 1519 and 23S rRNA nucleotides 745, 1915) and are excluded from downstream analysis. DMS modification rates and error were computed as described, ${ }^{17}$ with a 2-fold change cutoff.

\section{Modeling of Evn P}

The structures of the macrolides tylosin (PDB ID 1K9M) ${ }^{20}$ and erythromycin (PDB ID 3OFO) $)^{21}$ as well as the orthosomycin everninomicin (PDB ID 5KCS) ${ }^{22}$ were fitted to the cryo-EM map density of the EvnP-70S complex (EMD-3525) and used in $\operatorname{Coot}^{23}$ to generate molecular models for the rosamicin and everninomicin parts of Evn P, respectively.

\section{Toeprinting assay}

The position of the ribosome on the mRNA was monitored using a toe-printing assay based on the in vitro coupled transcription-translation system using the PURExpress in vitro protein synthesis kit (NEB) based on the protocol described previously. ${ }^{24-26}$ Briefly, each translation reaction consisted of $2 \mu \mathrm{L}$ Solution $\mathrm{A}$, $1.5 \mu \mathrm{L}$ Solution $\mathrm{B}, 1 \mu \mathrm{L}(0.5 \mathrm{pmol}) \mathrm{ermBL}$ template. Translation was performed in absence of isoleucine at $37^{\circ} \mathrm{C}$ for $15 \mathrm{~min}$ at $500 \mathrm{rpm}$ in $200 \mu \mathrm{L}$ PCR tubes. Ile-tRNA aminoacylation was further prevented by the 
use of the Ile-tRNA synthetase inhibitor mupirocin. After translation, 2 pmol Alexa647 labeled ErmBLtoeprint primer was added to each reaction and incubated at $37^{\circ} \mathrm{C}$ without shaking for $5 \mathrm{~min}$. Reverse transcription was performed using $1 \mu \mathrm{L}$ of AMV RT (NEB), $0.2 \mu \mathrm{L}$ dNTP mix (10 mM) and $0.8 \mu \mathrm{L}$ Pure System Buffer and incubated at $37^{\circ} \mathrm{C}$ for $20 \mathrm{~min}$. Reverse transcription was quenched and RNA degraded by addition of $1 \mu \mathrm{L} 10 \mathrm{M} \mathrm{NaOH}$ and incubation for at least $15 \mathrm{~min}$ at $37^{\circ} \mathrm{C}$ and then neutralized using $0.82 \mu \mathrm{L}$ of $12 \mathrm{M} \mathrm{HCl} .20 \mu \mathrm{L}$ toe-print resuspension buffer and $200 \mu \mathrm{L}$ PN1 buffer were added to each reaction before being treated with a QIAquick Nucleotide Removal Kit (Qiagen). The Alexa647 labeled DNA was then eluted from the QIAquick columns with $80 \mu \mathrm{L}$ of nuclease-free water. A vacuum concentrator was used to vaporize the solvent and the Alexa647 DNA was then dissolved into $3.5 \mu \mathrm{L}$ of formamide dye. The samples were heated to $95^{\circ} \mathrm{C}$ for $5 \mathrm{~min}$ before being applied onto a $6 \%$ polyacrylamide (19:1) sequencing gel containing $7 \mathrm{M}$ urea. Gel-electrophoresis was performed at $30 \mathrm{~W}$ and $600 \mathrm{~V}$ for 2.5 hours. The GE Typhoon FLA9500 imaging system was subsequently used to scan the polyacrylamide gel.

\section{In vitro translation using wildtype and mutant ribosomes}

Plasmids pAM552 with the single mutations A2058G or A2471C as well as the double mutation A2058G/A2471C in 23S rRNA operon were generated by site-directed mutagenesis of the wildtype 23S rRNA encoded on the pAM552 plasmid (kindly provided by Prof. A.S. Mankin, Chicago). SQ171 $\Delta$ tolC (SQ171DTC) strain was transformed with the mutant plasmids and the cells were then cured of the wildtype plasmid pCSacB by plating onto an LB agar plates supplemented with $50 \mu \mathrm{g} / \mathrm{ml}$ ampicillin and $5 \%$ sucrose, as described previously. ${ }^{27-28}$ Cell-free in vitro translation extracts were generated from the SQ171DTC wildtype and mutant strains, as described previously, ${ }^{29-30}$ and used to monitor the expression of firefly luciferase (Fluc) reporter in the presence of increasing concentrations of inhibitor, as performed for other translation inhibitors. ${ }^{24,31-32}$ 
Figure S1A. Genetic map and table of the everninomicin gene cluster (Evn D shown) from Micromonospora carbonacea var. aurantiaca. Potential operonal units are minimally defined by transcriptional gene directionality, which is indicated by green (sense) and red (antisense), respectively. (GenBank Nucleotide Accession: CP058322.1, genome region 866393-925867)

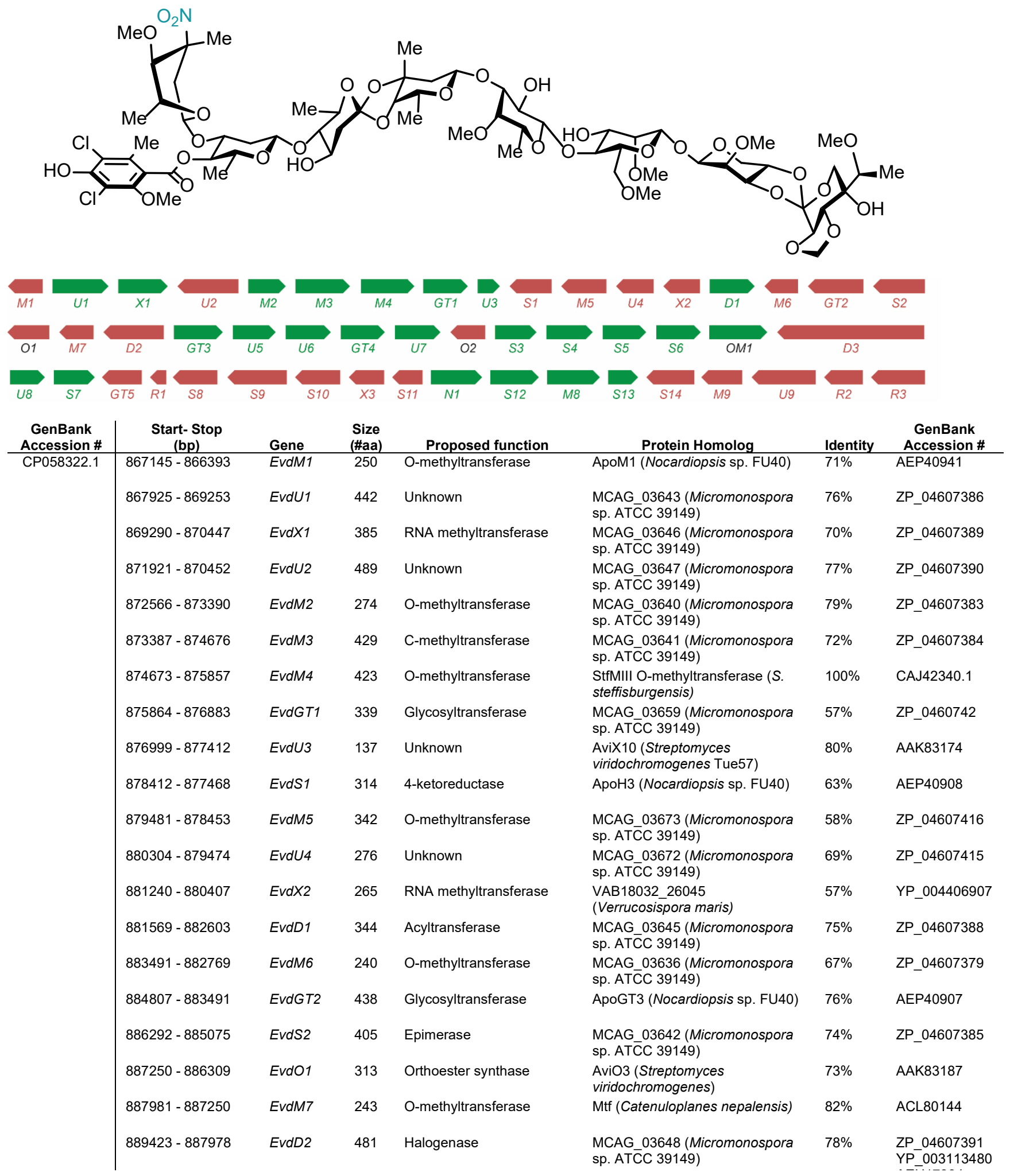




\begin{tabular}{|c|c|c|c|c|c|c|c|}
\hline \multirow[t]{30}{*}{ СР058322.1 } & $889737-890879$ & EvdGT3 & 380 & Glycosyltransferase & $\begin{array}{l}\text { MCAG_03663 (Micromonospora } \\
\text { sp. ATCC } 39149 \text { ) }\end{array}$ & $61 \%$ & ZP_04607406 \\
\hline & $890957-891934$ & EvdU5 & 325 & Pyruvate dehydrogenase & Dhg (Catenuloplanes nepalensis) & $89 \%$ & ACL80142 \\
\hline & $891939-892901$ & EvdU6 & 344 & Pyruvate dehydrogenase & $\begin{array}{l}\text { AviB2 (Streptomyces } \\
\text { viridochromogenes) }\end{array}$ & $77 \%$ & AAK83191 \\
\hline & $892949-893962$ & EvdGT4 & 337 & Glycosyltransferase & $\begin{array}{l}\text { AviGT3 (Streptomyces } \\
\text { viridochromogenes) }\end{array}$ & $75 \%$ & AAK83192 \\
\hline & $893959-895011$ & EvdU7 & 350 & Unknown & $\begin{array}{l}\text { MCAG_03660 (Micromonospora } \\
\text { sp. ATCC 39149) }\end{array}$ & $64 \%$ & ZP_04607403 \\
\hline & $895789-895031$ & EvdO2 & 252 & Orthoester synthase & $\begin{array}{l}\text { MCAG_03658 (Micromonospora } \\
\text { sp. ATCC 39149) }\end{array}$ & $71 \%$ & ZP_04607401 \\
\hline & $896144-897073$ & EvdS3 & 309 & Epimerase/dehydratase & $\begin{array}{l}\text { UUA_15808 (Rhodanobacter } \\
\text { thiooxydans) }\end{array}$ & $42 \%$ & ZP_10205860 \\
\hline & $897271-898338$ & EvdS4 & 355 & $\begin{array}{l}\text { Glucose-1-phosphate } \\
\text { thymidyltransferase }\end{array}$ & $\begin{array}{l}\text { MCAG_03630 (Micromonospora } \\
\text { sp. ATCC } 39149 \text { ) }\end{array}$ & $79 \%$ & ZP_04607373 \\
\hline & $898338-899327$ & EvdS5 & 329 & 4,6-dehydratase & $\begin{array}{l}\text { MCAG_03631 (Micromonospora } \\
\text { sp. ATCC } 39149 \text { ) }\end{array}$ & $78 \%$ & ZP_04607374 \\
\hline & $899382-900410$ & EvdS6 & 342 & 4-epimerase & $\begin{array}{l}\text { AviQ2 (Streptomyces } \\
\text { viridochromogenes) }\end{array}$ & $82 \%$ & AAK83170 \\
\hline & 900465- 901817 & EvdMO1 & 450 & Oxidase/Methyltransferase & $\begin{array}{l}\text { MCAG_03633 (Micromonospora } \\
\text { sp. ATCC 39149) }\end{array}$ & $77 \%$ & ZP_04607376 \\
\hline & $905775-901972$ & EvdD3 & 1267 & Polyketide synthase & $\begin{array}{l}\text { AviM (Streptomyces } \\
\text { viridochromogenes) }\end{array}$ & $65 \%$ & AAK83194 \\
\hline & $906255-907004$ & EvdU8 & 249 & Unknown & $\begin{array}{l}\text { MCAG_03657 (Micromonospora } \\
\text { sp. ATCC 39149) }\end{array}$ & $64 \%$ & ZP_04607400 \\
\hline & $907001-907924$ & EvdS7 & 307 & 4-ketoreductase & $\begin{array}{l}\text { MCAG_03656 (Micromonospora } \\
\text { sp. ATCC } 39149 \text { ) }\end{array}$ & $66 \%$ & ZP_04607399 \\
\hline & $908790-907903$ & EvdGT5 & 295 & Glycosyltransferase & $\begin{array}{l}\text { MCAG_03655 (Micromonospora } \\
\text { sp. ATCC } 39149 \text { ) }\end{array}$ & $80 \%$ & ZP_04607398 \\
\hline & $909100-908852$ & EvdR1 & 82 & Regulator & $\begin{array}{l}\text { MCAG_03654 (Micromonospora } \\
\text { sp. ATCC } 39149 \text { ) }\end{array}$ & $82 \%$ & ZP_04607397 \\
\hline & $910949-909924$ & EvdS8 & 341 & 3-ketoreductase & $\begin{array}{l}\text { MCAG_03652 (Micromonospora } \\
\text { sp. ATCC 39149) }\end{array}$ & $68 \%$ & ZP_04607395 \\
\hline & $912358-910946$ & EvdS9 & 470 & 2,3-dehydratase & $\begin{array}{l}\text { MCAG_03651 (Micromonospora } \\
\text { sp. ATCC 39149) }\end{array}$ & $70 \%$ & ZP_04607394 \\
\hline & $913395-912355$ & EvdS10 & 346 & 4,6-dehydratase & $\begin{array}{l}\text { MCAG_03650 (Micromonospora } \\
\text { sp. ATCC } 39149 \text { ) }\end{array}$ & $76 \%$ & ZP_04607392 \\
\hline & $914363-913599$ & $E v d X 3$ & 254 & RNA Methyltransferase & $\begin{array}{l}\text { MCAG_03674 (Micromonospora } \\
\text { sp. ATCC 39149) }\end{array}$ & $71 \%$ & ZP_04607417 \\
\hline & $\begin{array}{l}915400-914462 \\
480-1\end{array}$ & EvdS11 & 209 & UDP-glucose 4-epimerase & $\begin{array}{l}\text { MCAG_03662 (Micromonospora } \\
\text { sp. ATCC 39149) }\end{array}$ & $74 \%$ & ZP_04607405 \\
\hline & $915794-916996$ & EvdN1 & 400 & Nitrososynthase & $\begin{array}{l}\text { ORF36 (Micromonospora sp. } \\
\text { ATCC 39149) }\end{array}$ & $80 \%$ & ACF94630 \\
\hline & $916993-918120$ & EvdS12 & 375 & 3-aminotransferase & $\begin{array}{l}\text { MCAG_03665 (Micromonospora } \\
\text { sp. ATCC 39149) }\end{array}$ & $79 \%$ & ZP_04607408 \\
\hline & $918150-919400$ & EvdM8 & 416 & C-methyltransferase & $\begin{array}{l}\text { MCAG_03666 (Micromonospora } \\
\text { sp. ATCC } 39149 \text { ) }\end{array}$ & $81 \%$ & ZP_04607409 \\
\hline & $919409-920032$ & EvdS13 & 207 & 3,5-epimerase & $\begin{array}{l}\text { MCAG_03667 (Micromonospora } \\
\text { sp. ATCC 39149) }\end{array}$ & $74 \%$ & ZP_04607410 \\
\hline & $920962-919853$ & EvdS14 & 369 & 4-ketoreductase & $\begin{array}{l}\text { StaK (Streptomyces sp. TP- } \\
\text { A0274) }\end{array}$ & $58 \%$ & BAC55215 \\
\hline & $921879-920959$ & EvdM9 & 306 & O-methyltransferase & $\begin{array}{l}\text { MCAG_03669 (Micromonospora } \\
\text { sp. ATCC 39149) }\end{array}$ & $71 \%$ & ZP_04607412 \\
\hline & $923604-922051$ & EvdU9 & 517 & Unknown & $\begin{array}{l}\text { MCAG_00021 (Micromonospora } \\
\text { sp. ATCC 39149) }\end{array}$ & $66 \%$ & ZP_04603764 \\
\hline & $924539-923679$ & EvdR2 & 286 & Regulator & $\begin{array}{l}\text { Amir_6179 (Actinosynnema } \\
\text { mirum) }\end{array}$ & $61 \%$ & YP_003103832 \\
\hline & $925867-924557$ & EvdR3 & 423 & Regulator & $\begin{array}{l}\text { AMED_3740 (Amycolatopsis } \\
\text { mediterranei) }\end{array}$ & $63 \%$ & YP_003765921 \\
\hline
\end{tabular}


Figure S1B. Map of pSET152ermE, the genetic complementation plasmid. Plasmid map was generated using Savvy (Scalable Vector Graphics \& Plasmid Map Copyright@ 2001, Malay K Basu) at http://www.bioinformatics.org/savvy/. Hyg is the hygromycin resistance marker hph; oriT is the origin of transfer; int is the phage $\varphi \mathrm{C} 31$ integrase; attP is the phage $\varphi \mathrm{C} 31$ attachment site; ermE* is the constitutively active promoter directly upstream of the multiple cloning site.

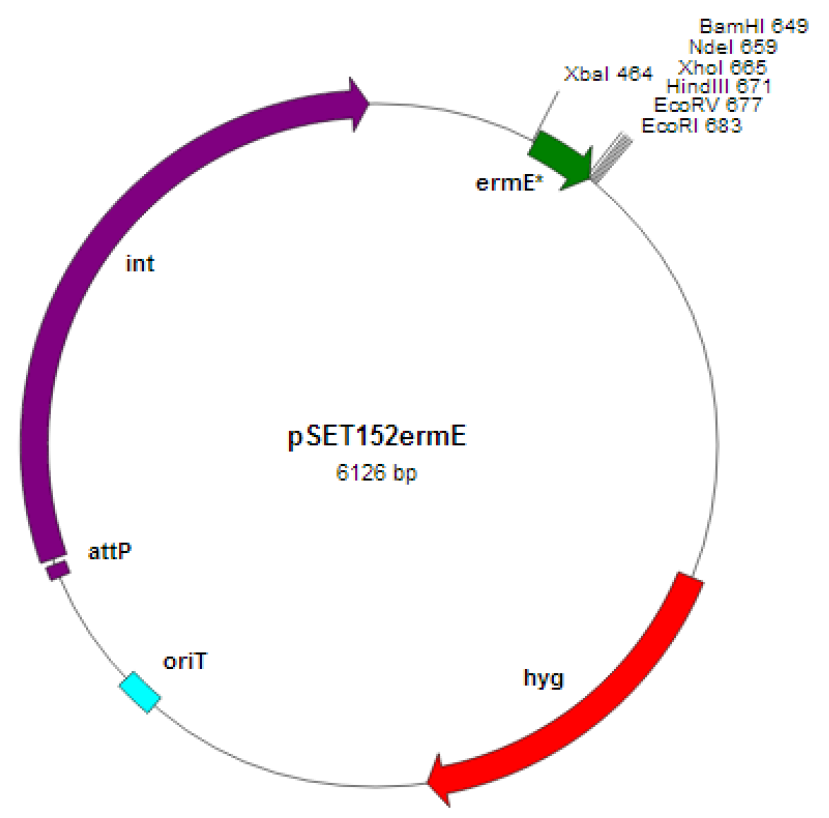

Figure S2. Southern hybridization of targeted replacement mutants verifying a double crossover. Ladder is DNA molecular weight marker VII, DIG-labeled (Roche Life Sciences, Product No. 11669940910). WT is wild-type $M$. carbonacea var. aurantiaca. Red bar indicates position of gene specific probes. Green bar indicates positions of apramycin cassette specific probes. Southern blot analysis of $\Delta$ evdN1::aac(3)IV. Diagrams show the expected relative shifts for replacement of evdN1 with the apramycin cassette. Xhol, EcoRV, and Apal are restriction endonucleases used to cleave the genomic DNA into predictable fragments. Predicted shifts were observed experimentally confirming the double crossover.
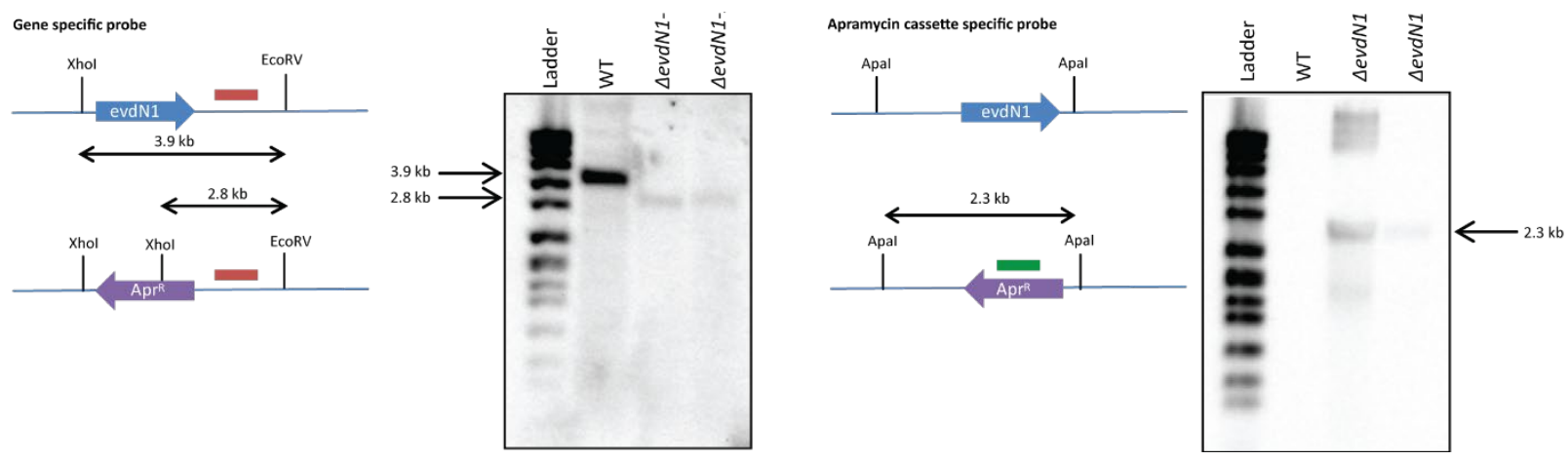
Figure S3. Everninomicin $\mathrm{N}$ mass spectrometric fragmentation data. Spectrum for fragmentation of Evn $\mathrm{N}$ $(\mathrm{m} / \mathrm{z}=1263.5)$.

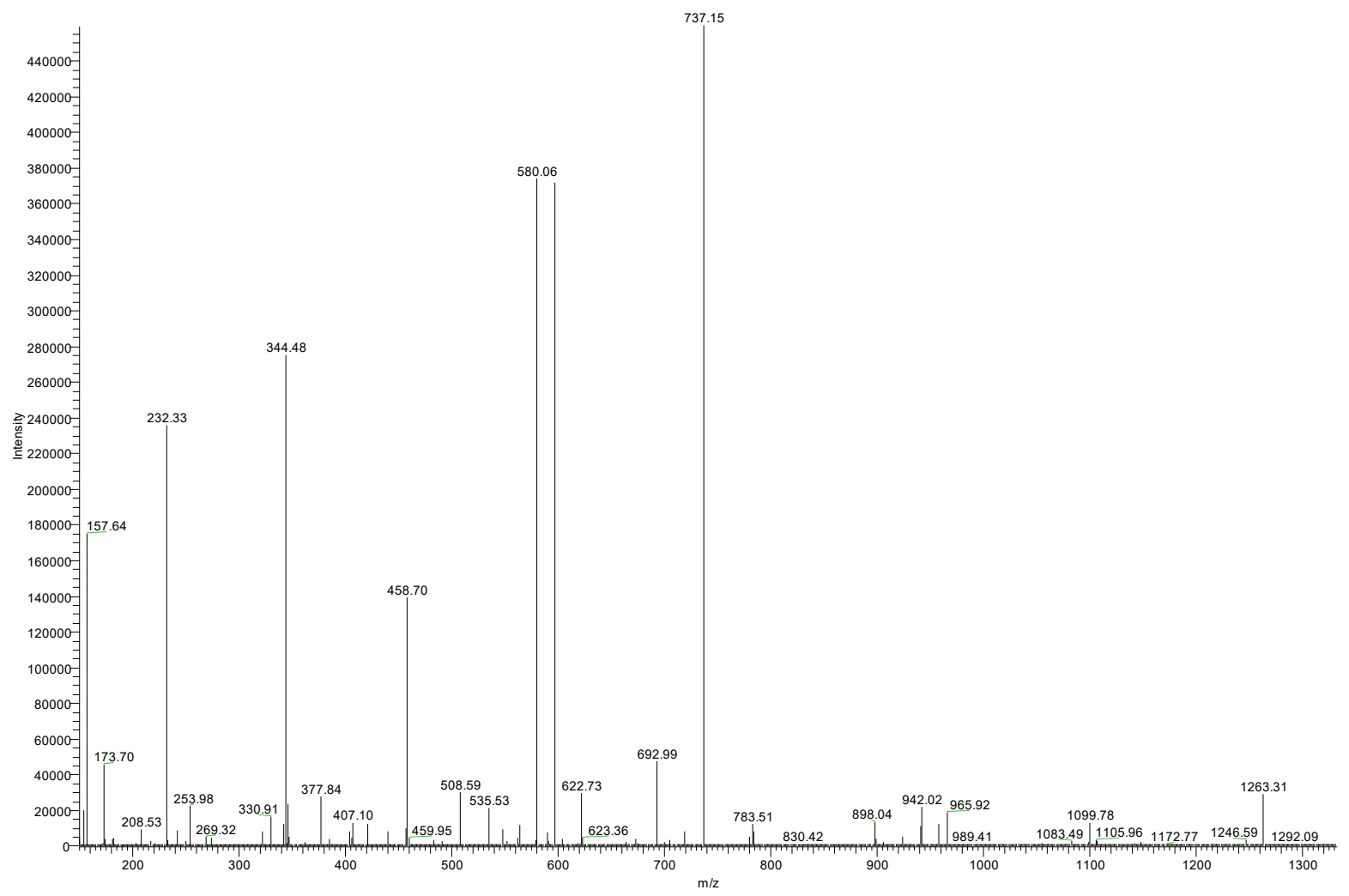


Figure S4. Everninomicin M mass spectrometric fragmentation data. (A) Mass spectrometric fragmentation pattern for Evn M. Dashed lines indicate positions of cleavage during fragmentation experiments. (B) Spectrum for fragmentation of Evn $M\left(m / z=1349.5[M+H]^{+}\right)$.
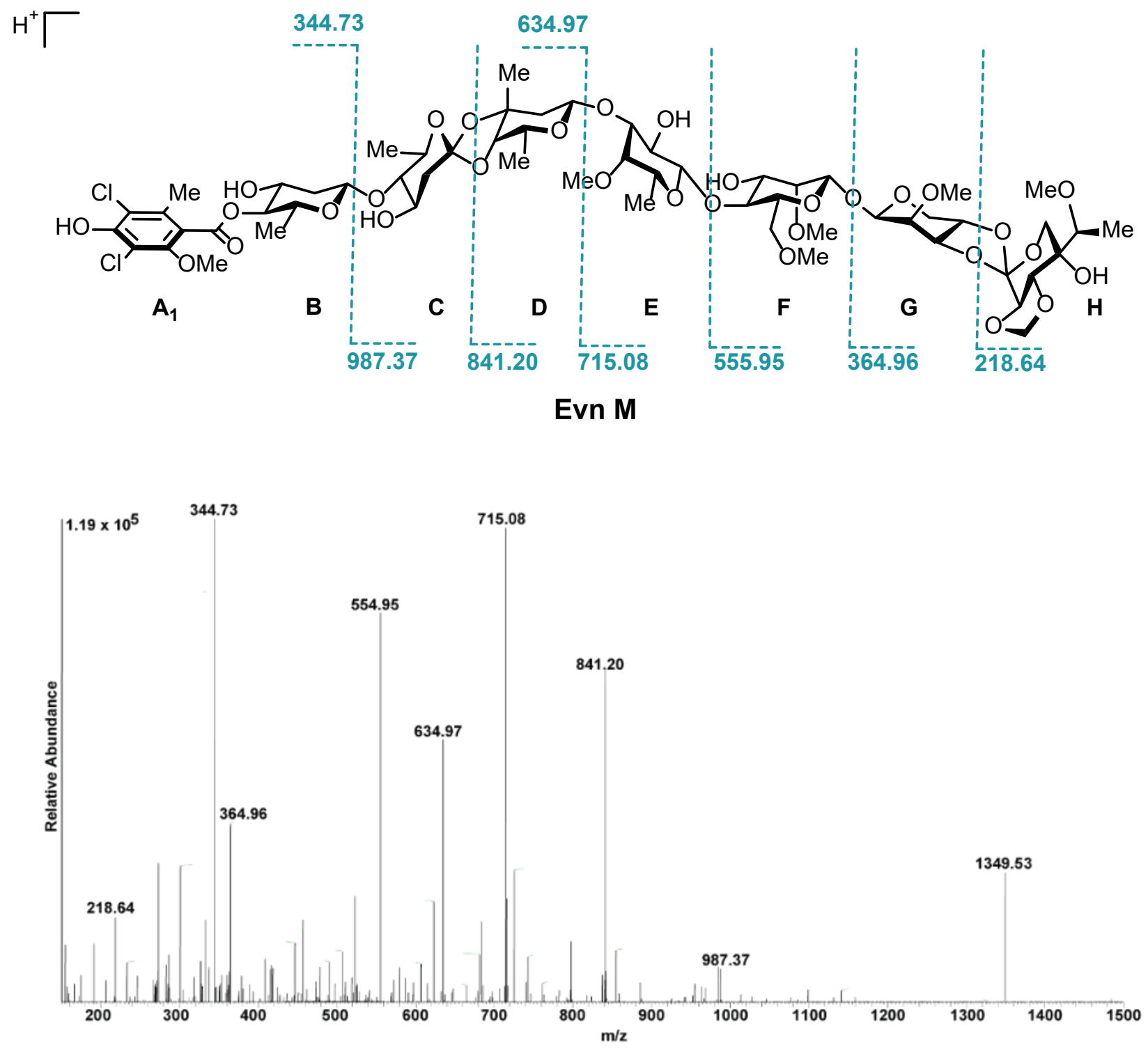
Figure S5. ${ }^{1} \mathrm{H}$ proton NMR of Evn $\mathrm{N}$ in $\mathrm{CD}_{4} \mathrm{OD}$.

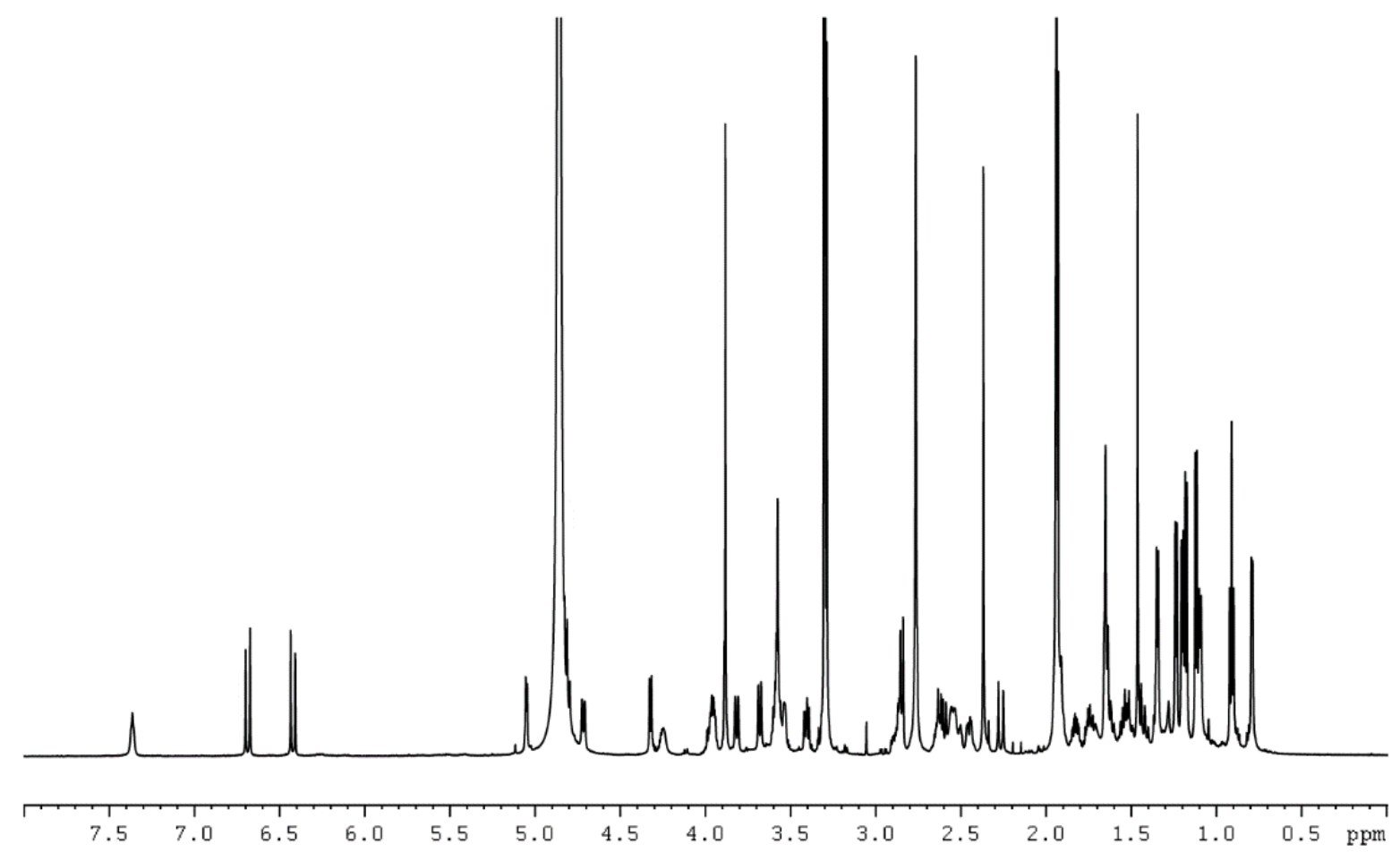

Figure S6. ${ }^{13} \mathrm{C}$ carbon NMR of Evn $\mathrm{N}$ in $\mathrm{CD}_{4} \mathrm{OD}$. 
Figure S7. COSY NMR of Evn $\mathrm{N}$ in $\mathrm{CD}_{4} \mathrm{OD}$.

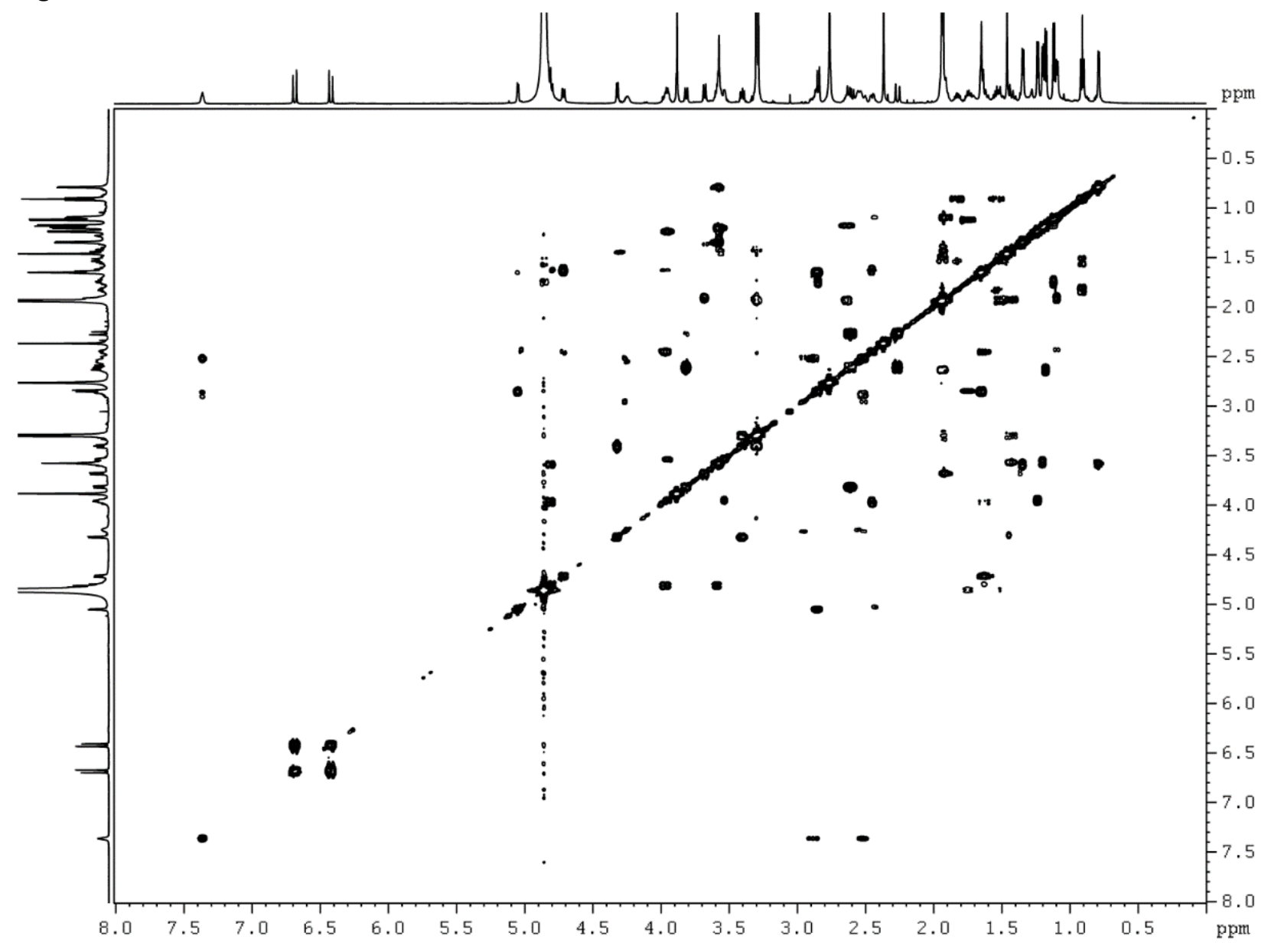


Figure S8. HSQC NMR of Evn $\mathrm{N}$ in $\mathrm{CD}_{4} \mathrm{OD}$.

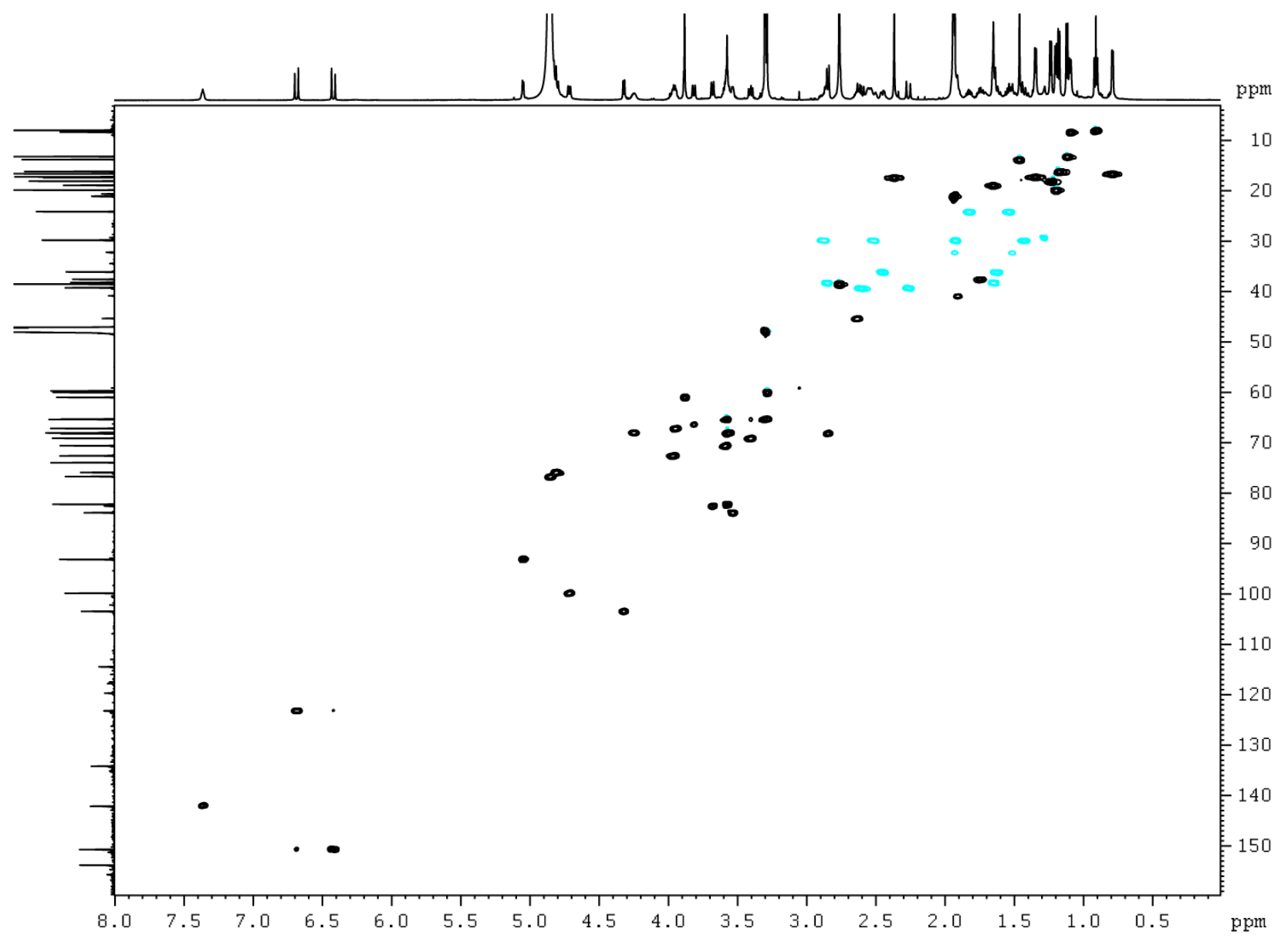


Figure S9. $\mathrm{HMBC}$ NMR of Evn $\mathrm{N}$ in $\mathrm{CD}_{4} \mathrm{OD}$.

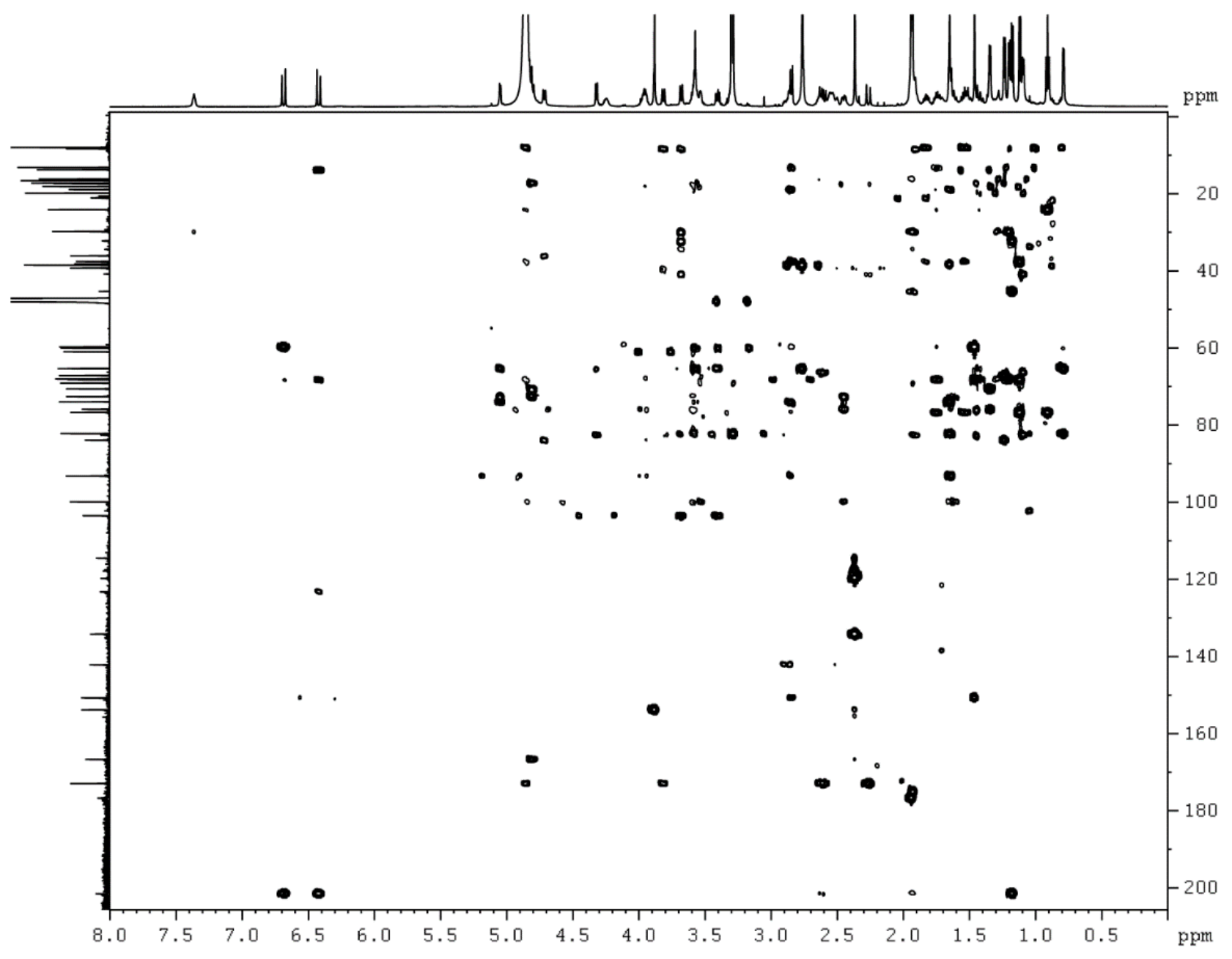


Figure S10. TOCSY NMR of Evn N in $\mathrm{CD}_{4} \mathrm{OD}$.

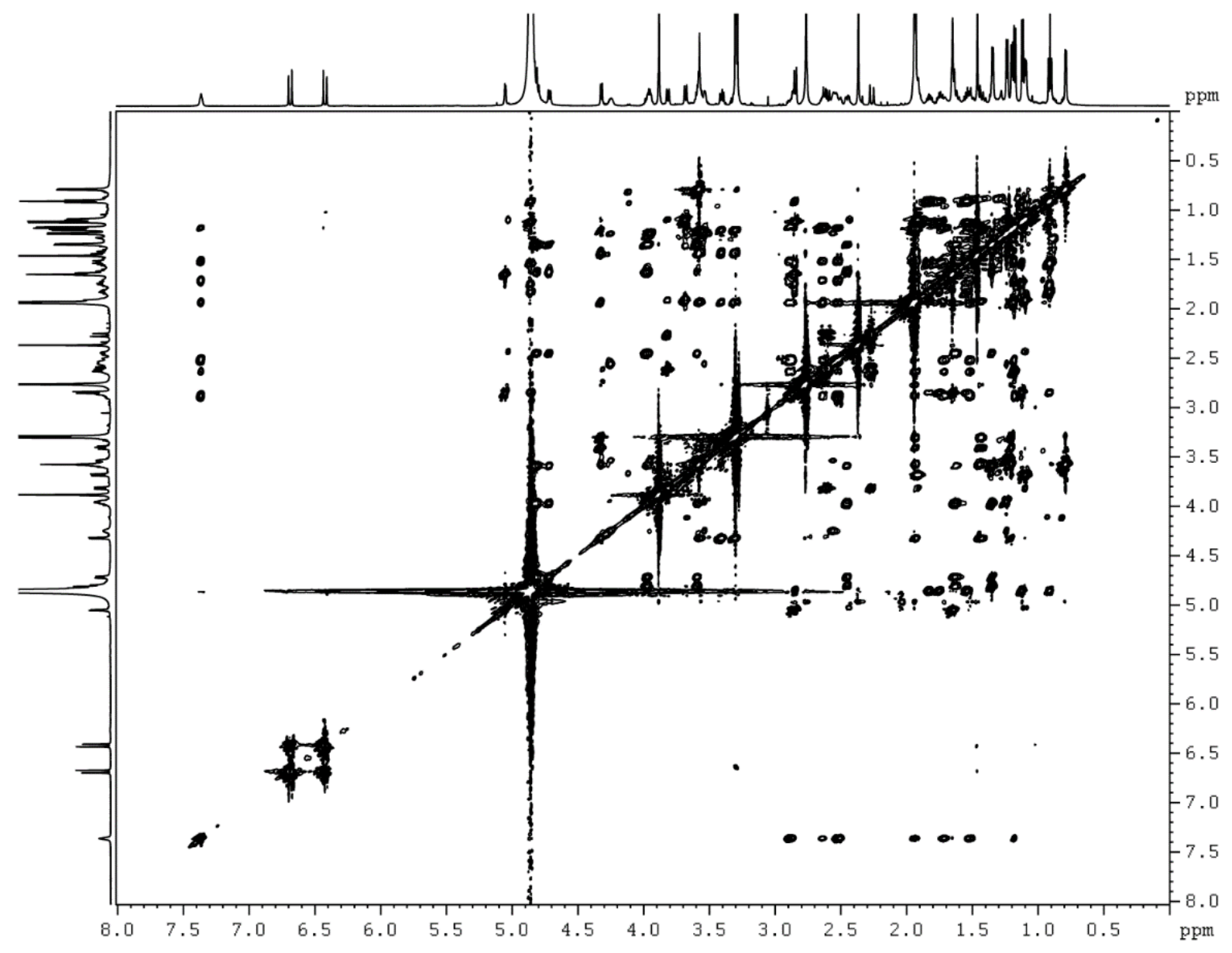


Figure S11. NOESY NMR of Evn N in $\mathrm{CD}_{4} \mathrm{OD}$.

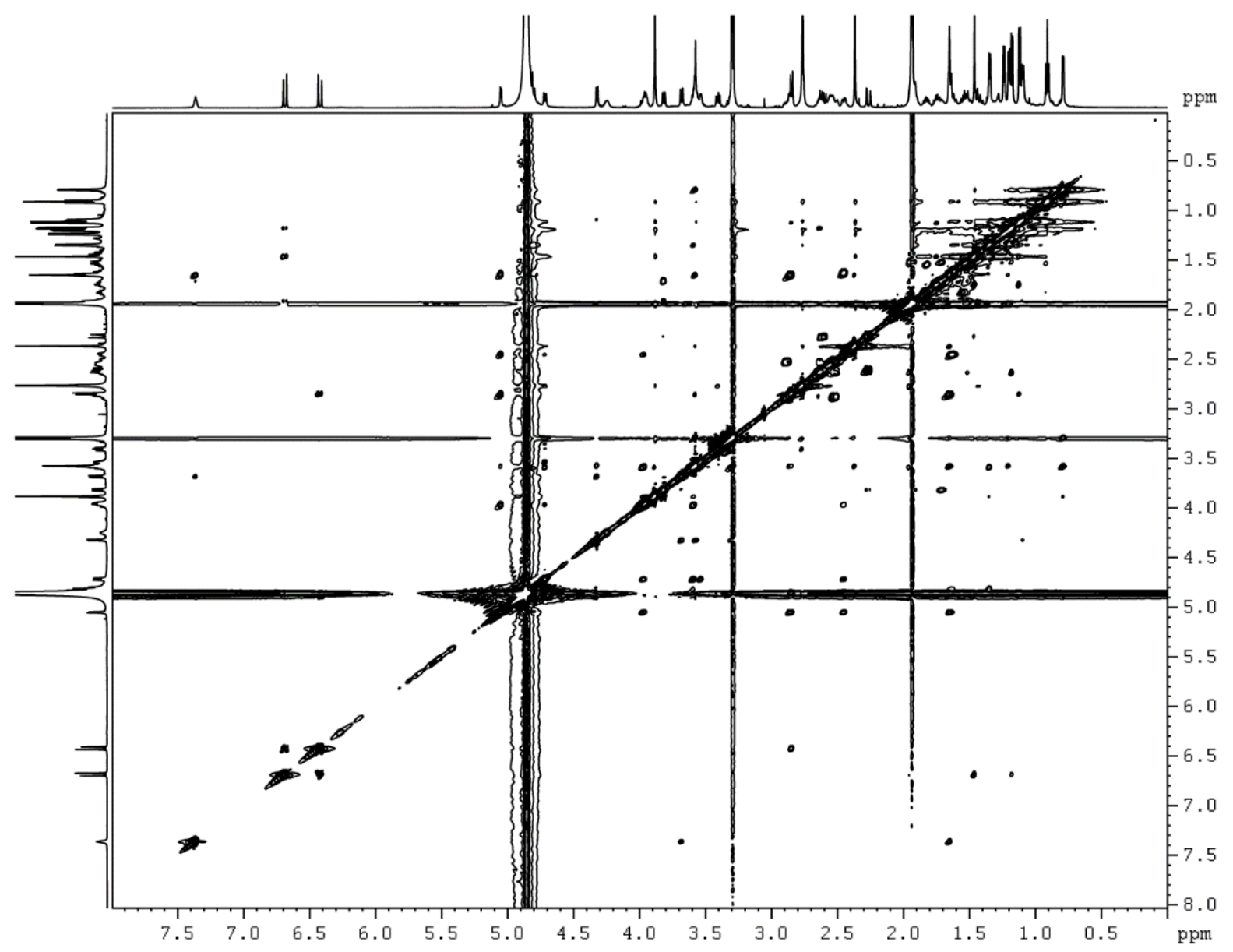


Figure S12. ${ }^{1} \mathrm{H}$ proton NMR of Evn $\mathrm{O}$ in $\mathrm{CD}_{4} \mathrm{OD}$.

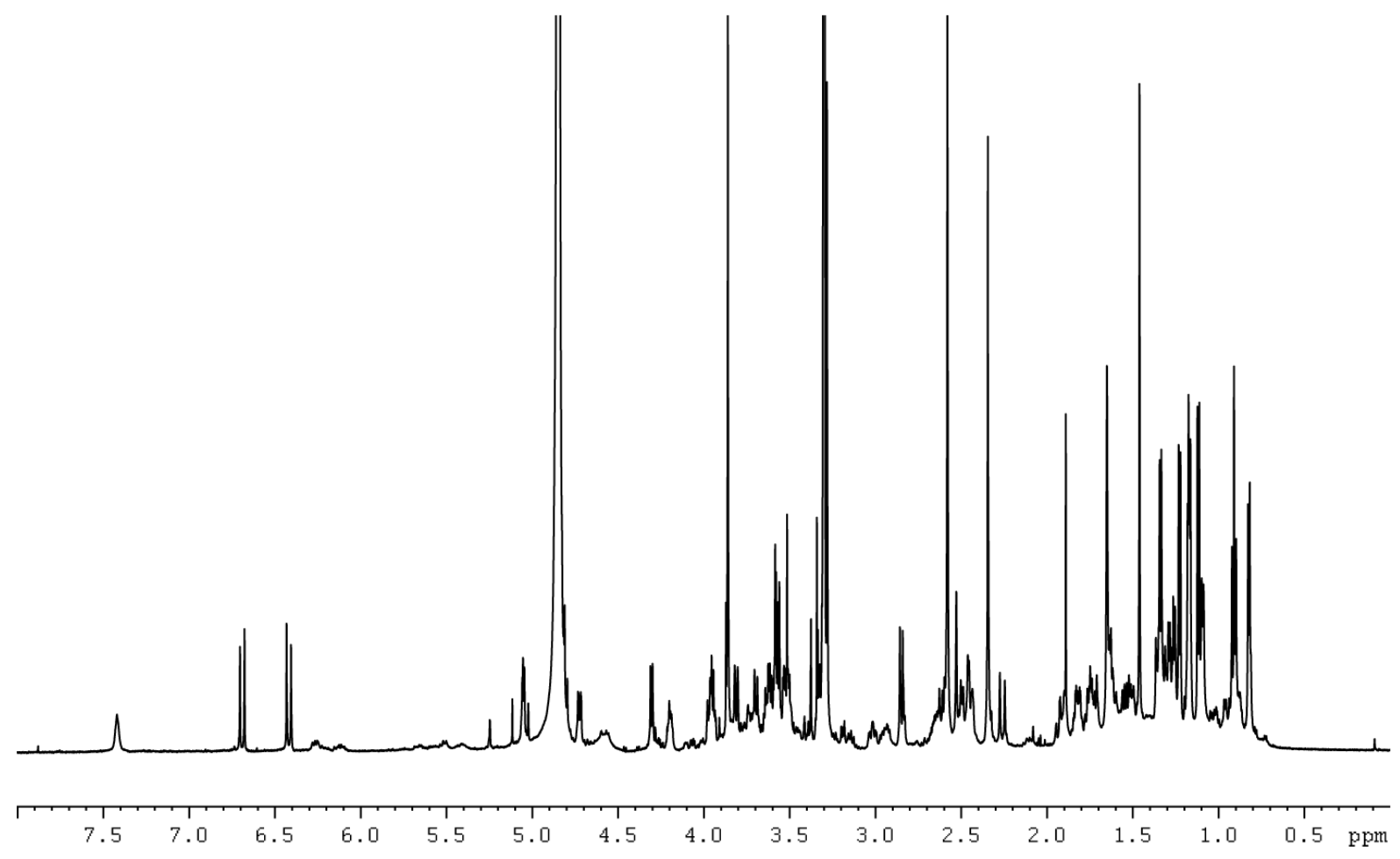


Figure S13. COSY NMR of Evn O in $\mathrm{CD}_{4} \mathrm{OD}$.

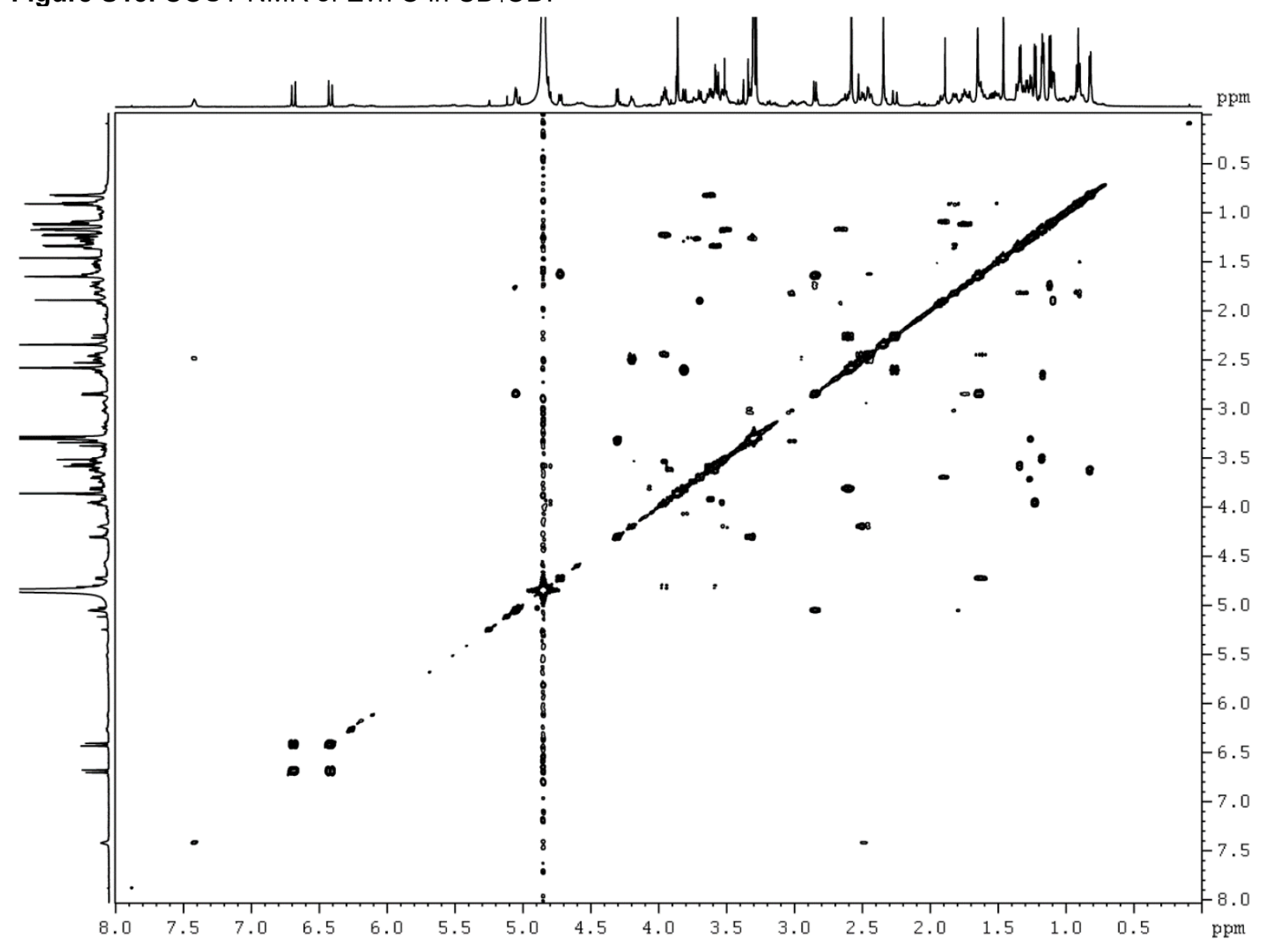


Figure S14. HSQC NMR of Evn O in $\mathrm{CD}_{4} \mathrm{OD}$.

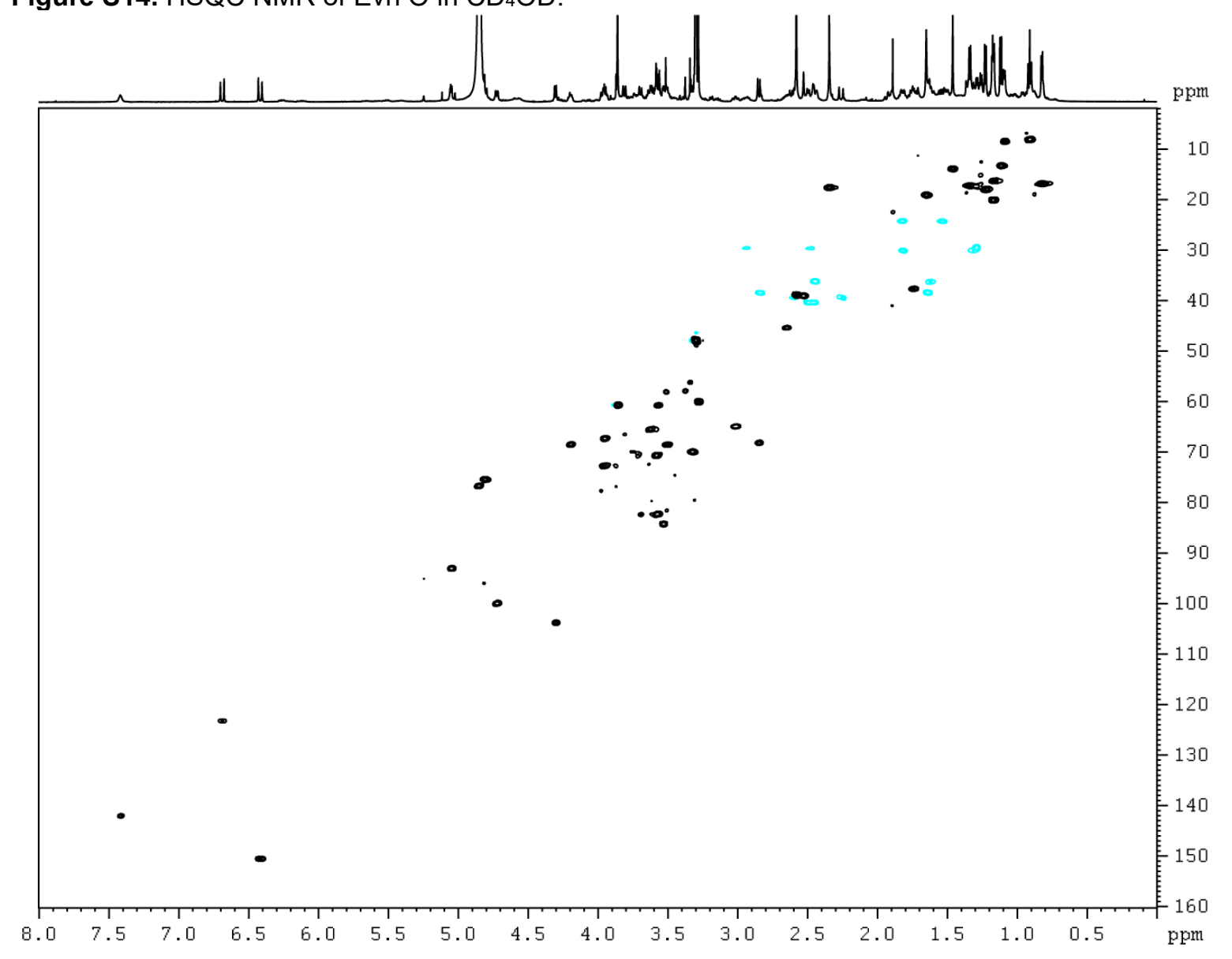


Figure S15. HMBC NMR of Evn O in $\mathrm{CD}_{4} \mathrm{OD}$.

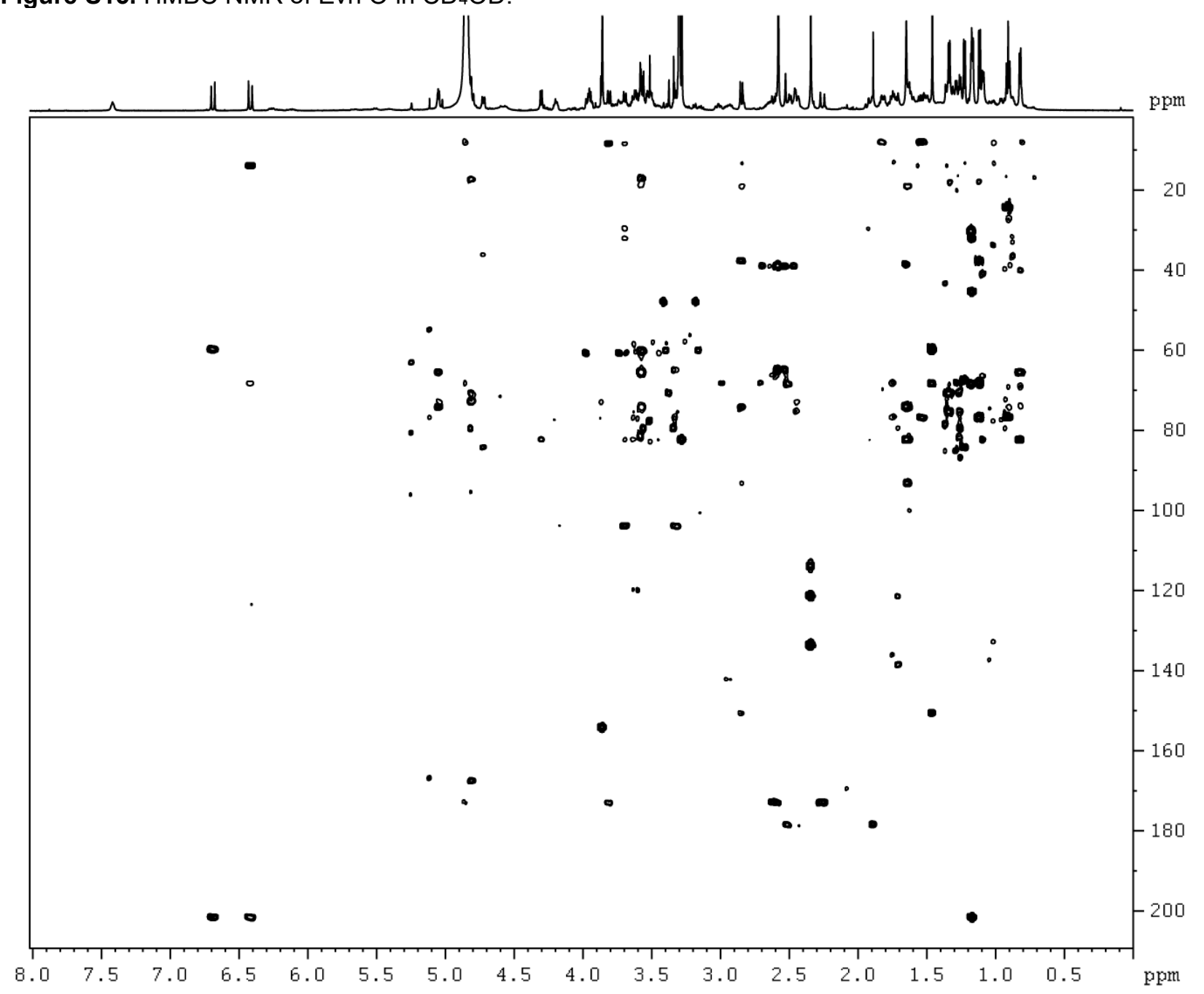


Figure S16. TOCSY NMR of Evn O in $\mathrm{CD}_{4} \mathrm{OD}$.

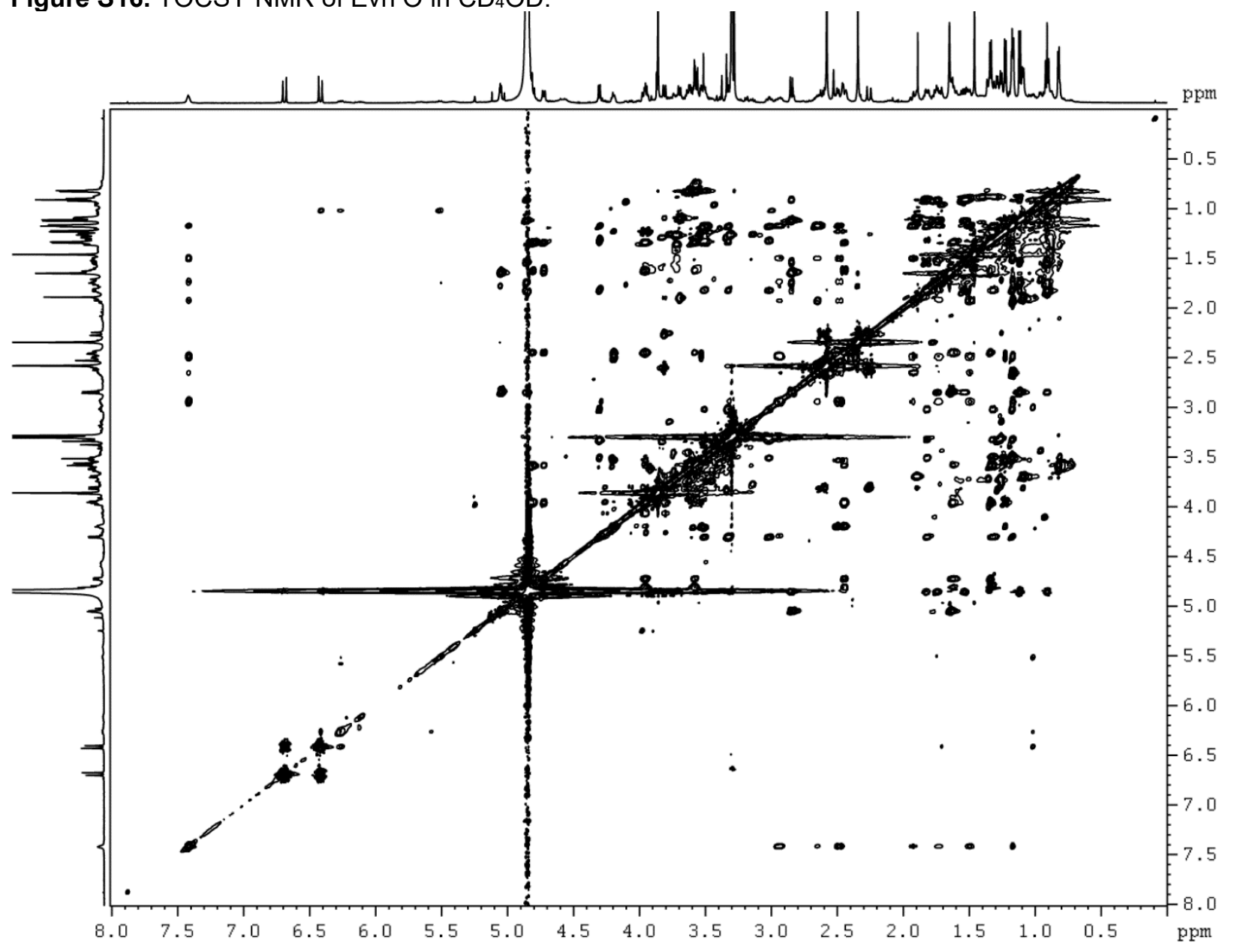


Figure S17. NOESY NMR of Evn O in $\mathrm{CD}_{4} \mathrm{OD}$.

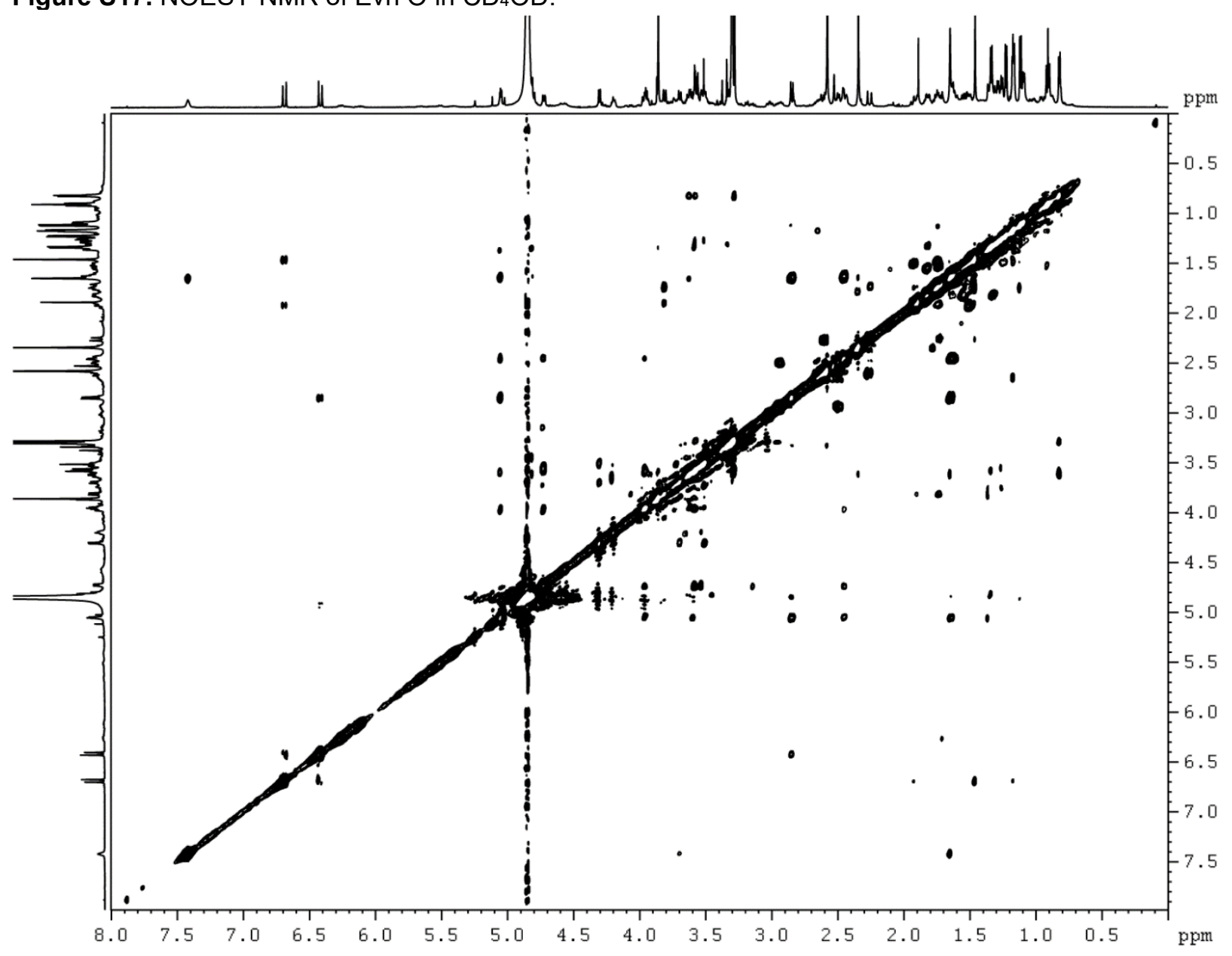


Figure S18. ${ }^{1} \mathrm{H}$ proton NMR of Evn $\mathrm{P}$ in $\mathrm{CD}_{4} \mathrm{OD}$.

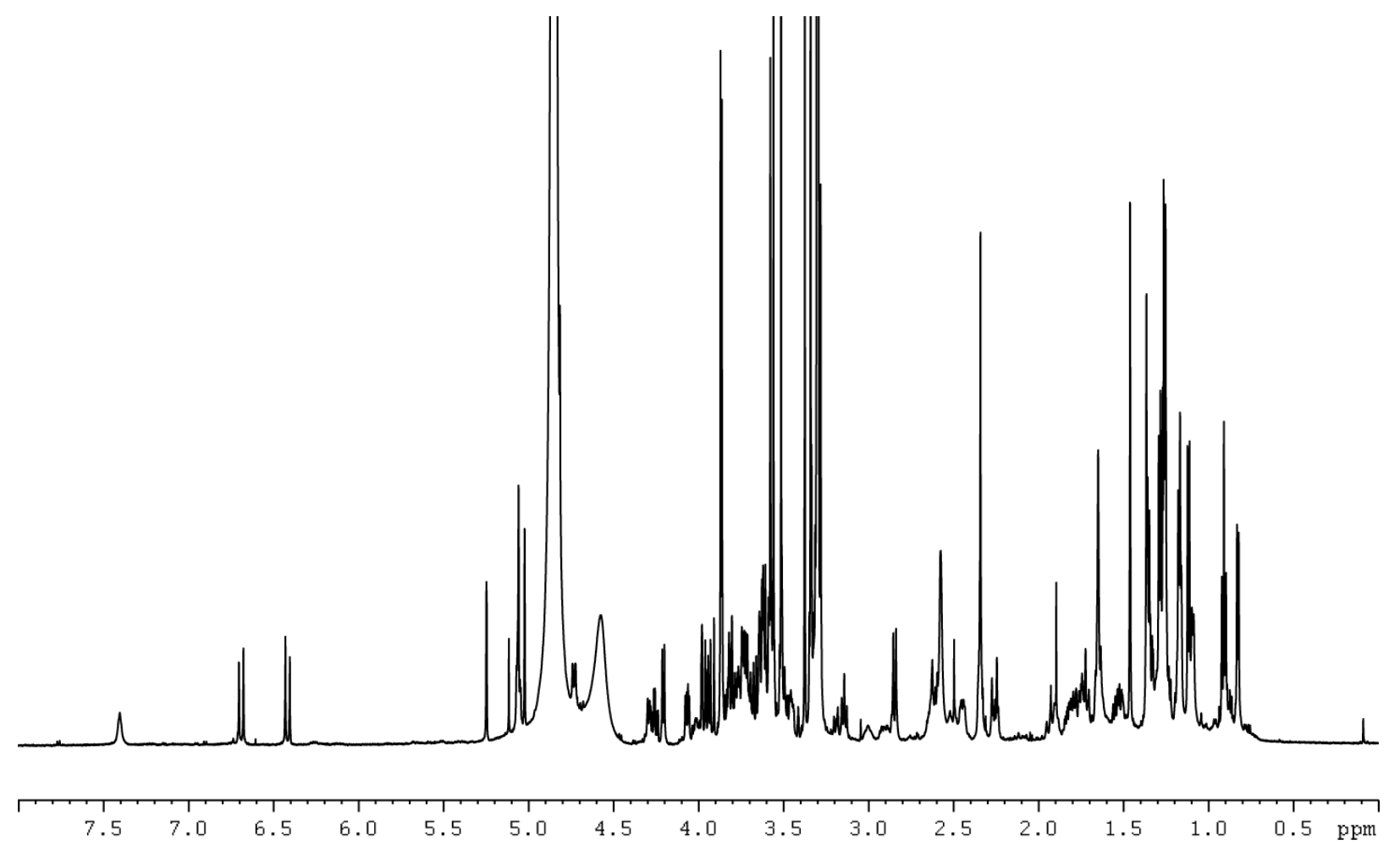


Figure S19. COSY NMR of Evn $\mathrm{P}$ in $\mathrm{CD}_{4} \mathrm{OD}$.

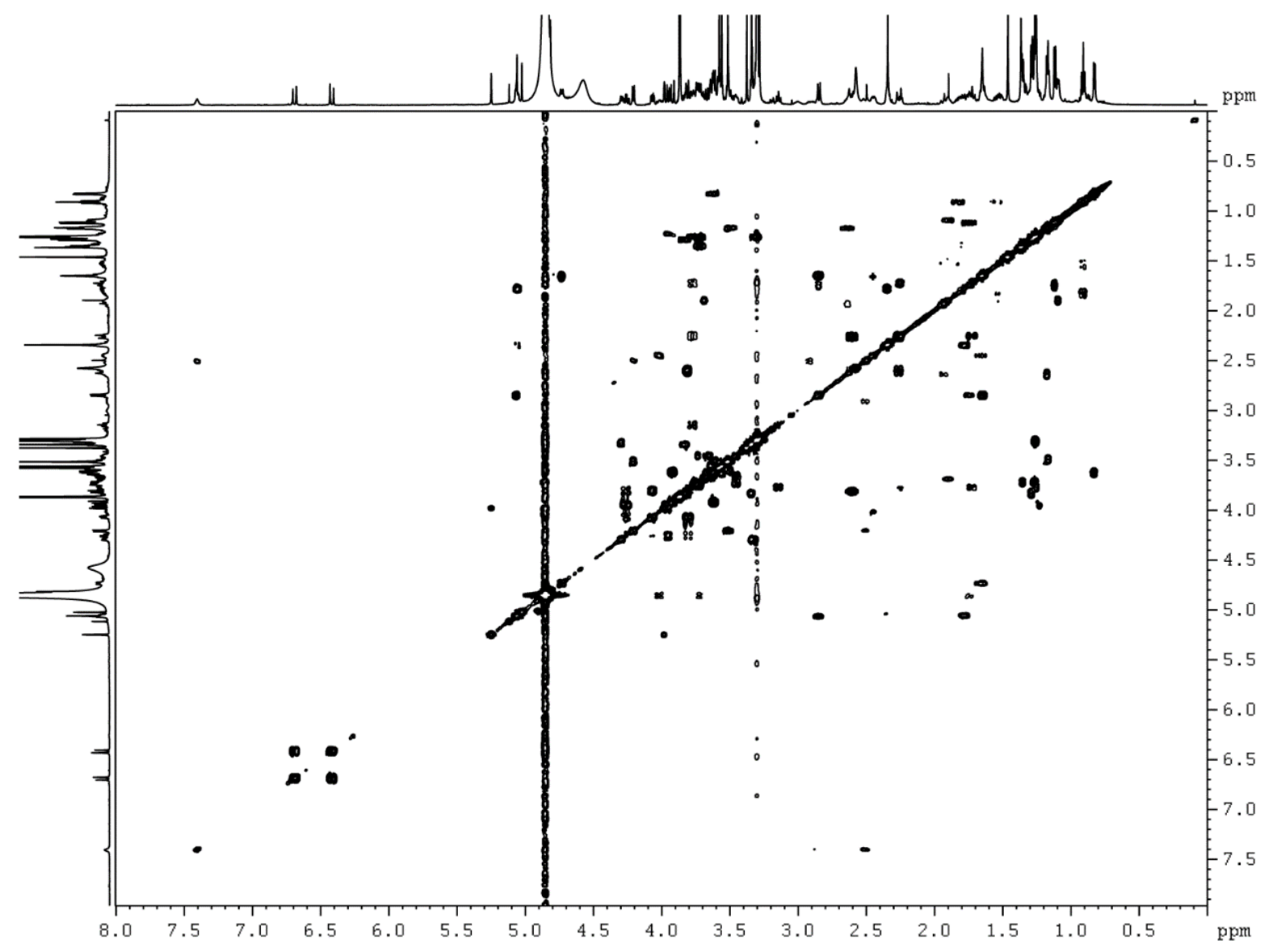


Figure S20. HSQC NMR of Evn $\mathrm{P}$ in $\mathrm{CD}_{4} \mathrm{OD}$.

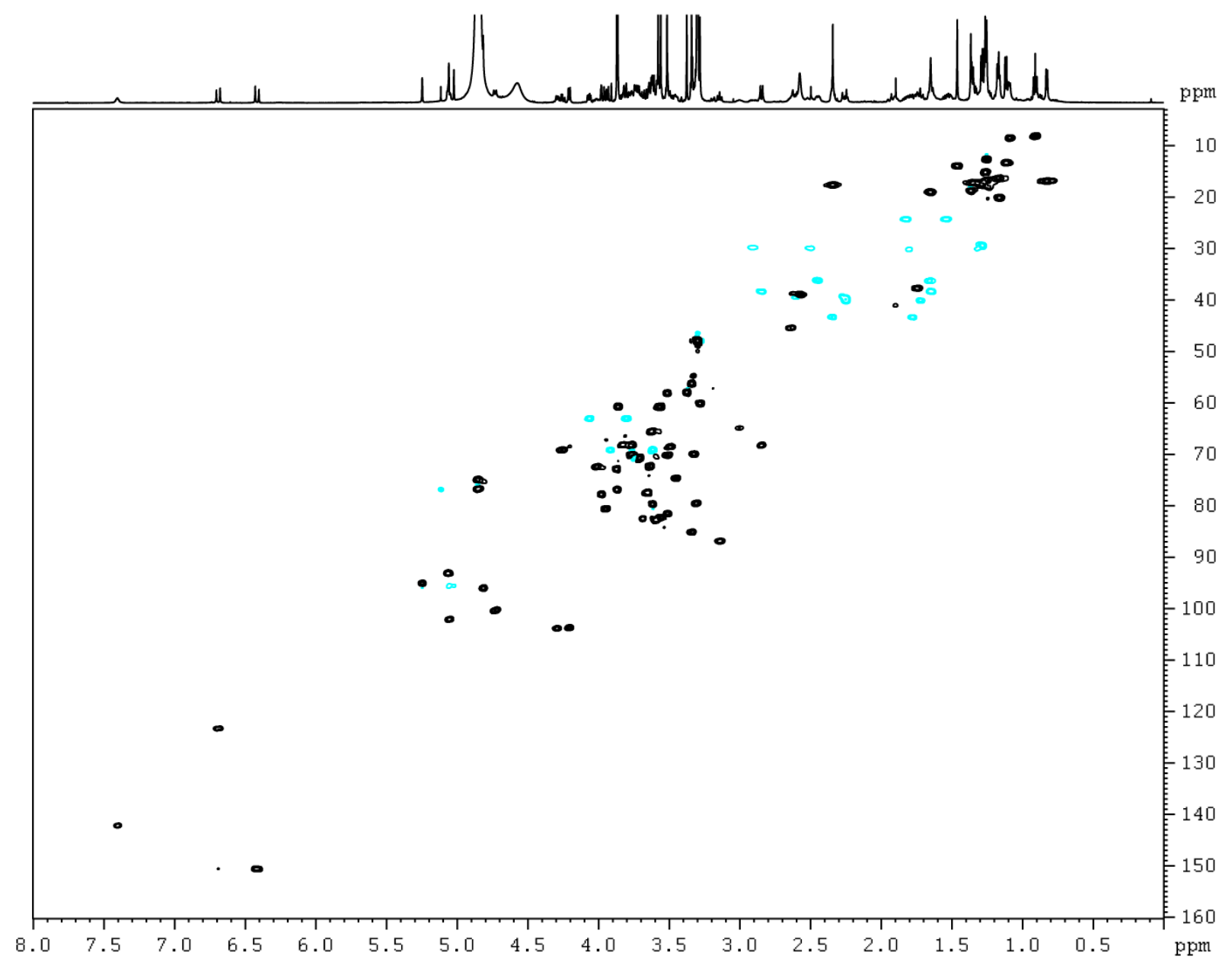


Figure S21. HMBC NMR of Evn $\mathrm{P}$ in $\mathrm{CD}_{4} \mathrm{OD}$.

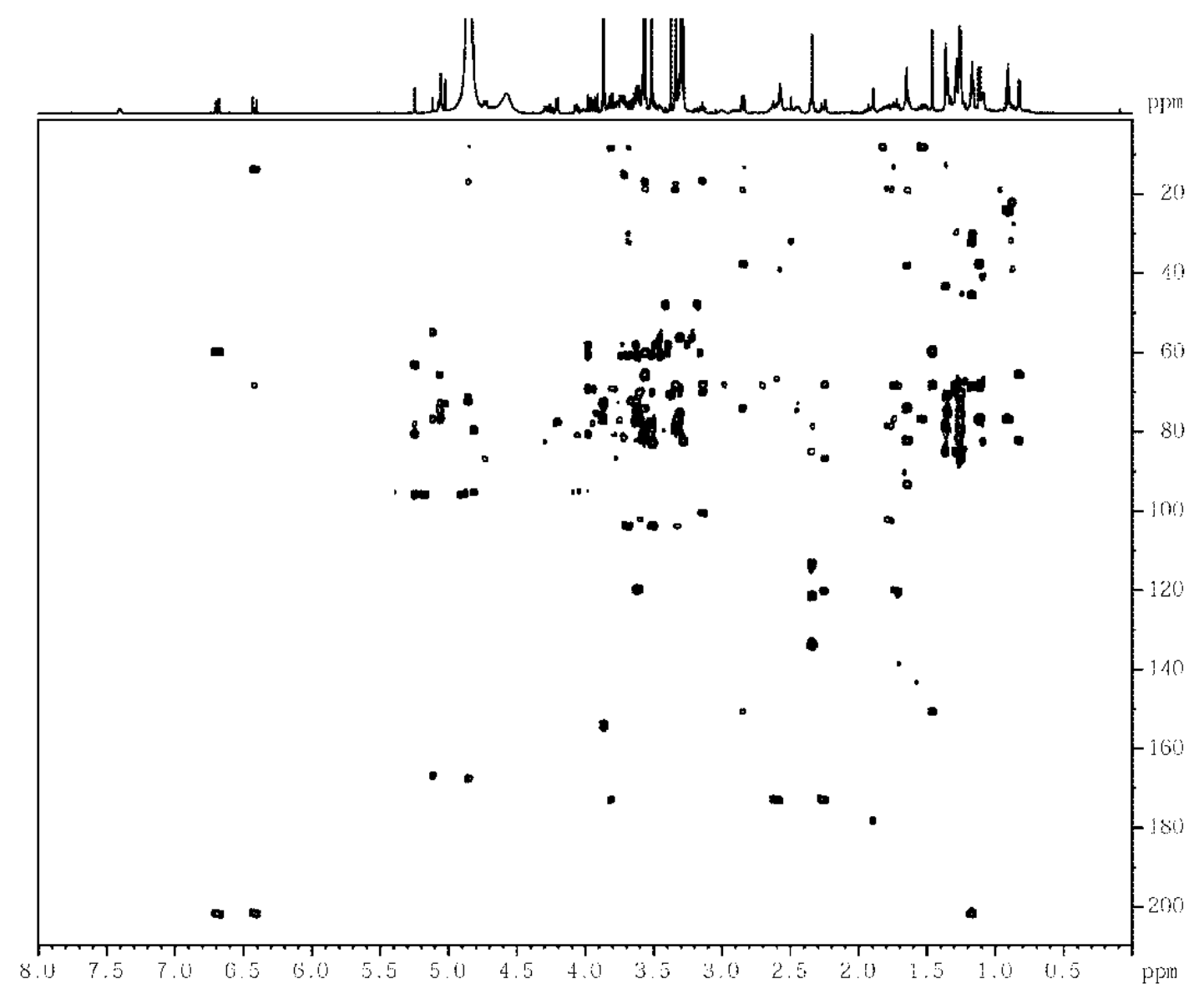


Figure S22. Degradation of full-length everninomicin-rosaramicin (Evn $P$ ). (A) Scheme shows the degradation of Evn $\mathrm{P}$ conjugate to the smaller trisaccharide, Evn N. (B) Chromatogram showing the increase over time in the degradation product, Evn N. TIC was filtered for $m / z=1263.5(\mathrm{M}+\mathrm{H})^{+}$. Inset shows the decrease over time in Evn P. TIC was filtered for $m / z=2086.5(\mathrm{M}+\mathrm{H})^{+}$.

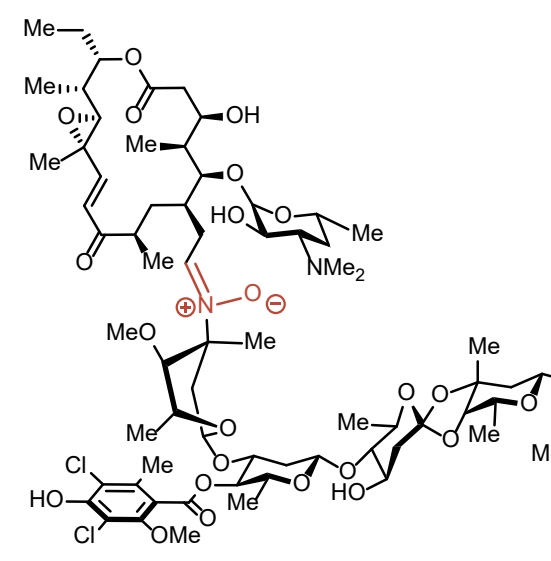

Evn $P$
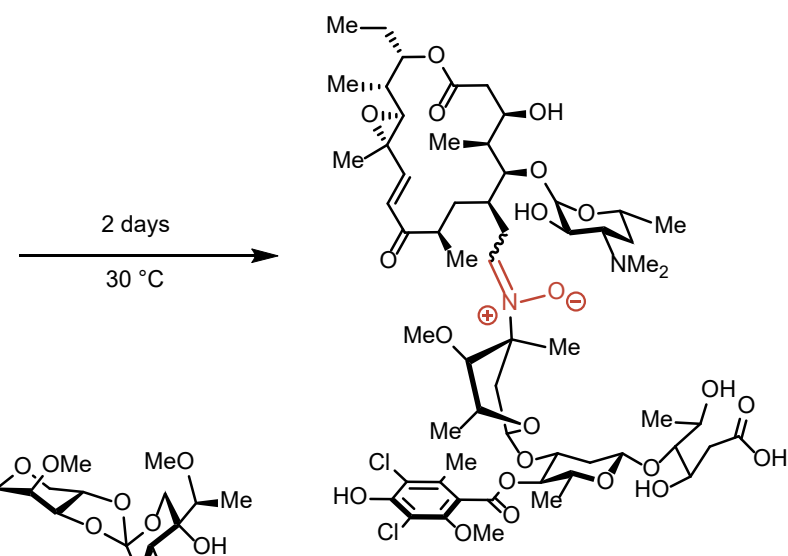

Evn $N(Z)$ and Evn $O(E)$

Ever P Degradation

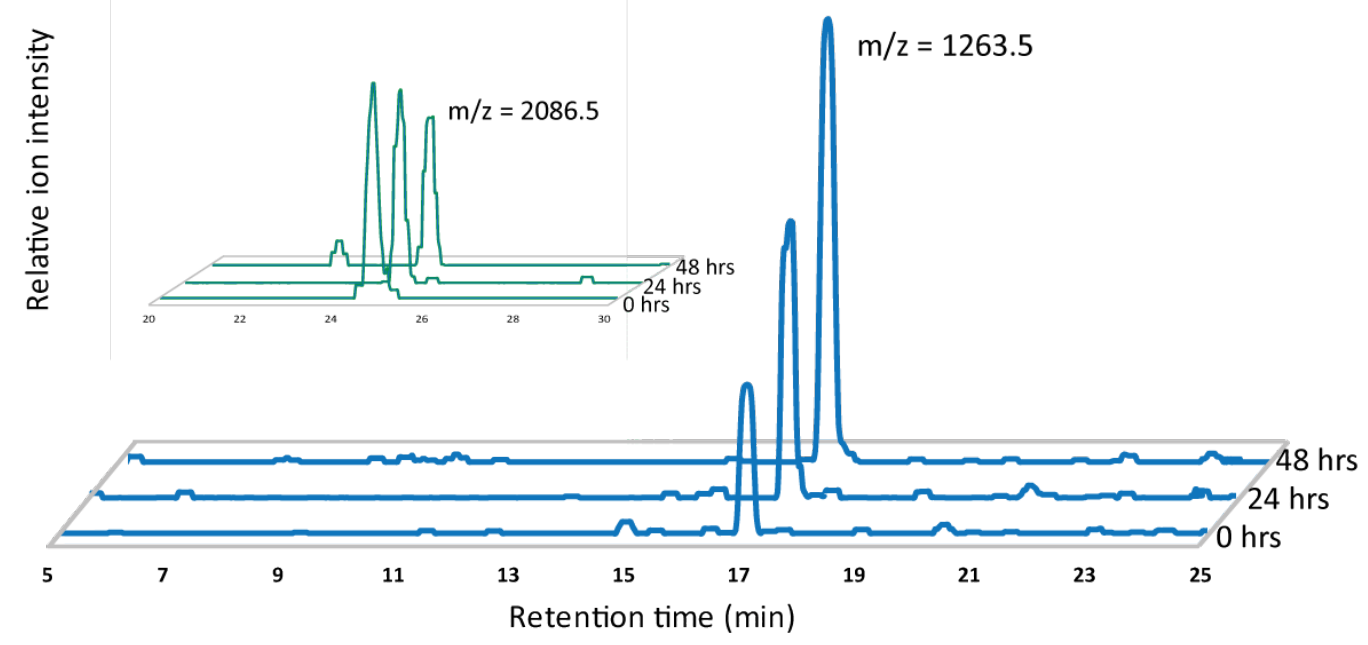


Figure S23. The minimal inhibitory concentration of each everninomicin analog was tested against $S$. aureus subsp. aureus Rosenbach. (A) Activity of Evn A against $S$. aureus subsp. aureus Rosenbach at various concentrations. (B) Activity of Evn $\mathrm{H}$ against $S$. aureus subsp. aureus Rosenbach at various concentrations. (C) Activity of Evn $\mathrm{N}$ against $\mathrm{S}$. aureus subsp. aureus Rosenbach at various concentrations. (D) Activity of Evn $\mathrm{O}$ against $S$. aureus subsp. aureus Rosenbach at various concentrations. (E) Activity of Evn $P$ against $S$. aureus subsp. aureus Rosenbach at various concentrations.

A

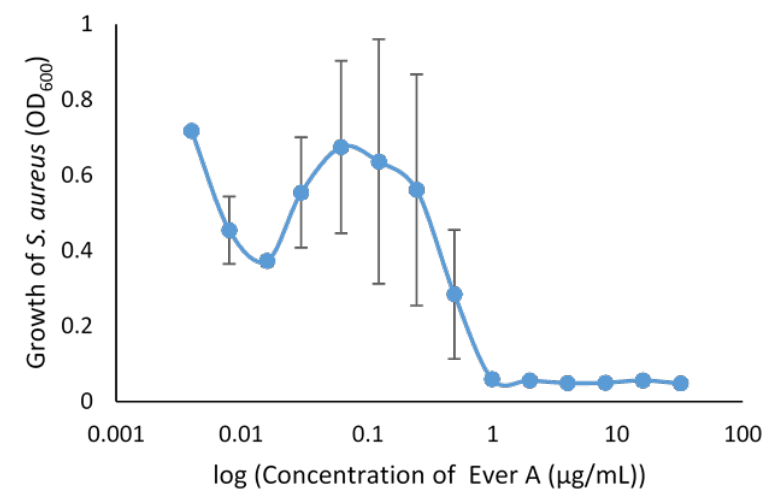

C Ever N Bioactivity

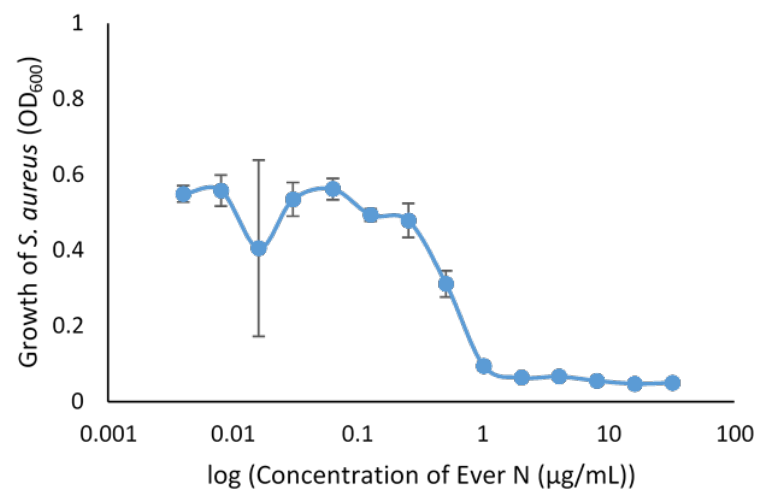

E Ever P Bioactivity

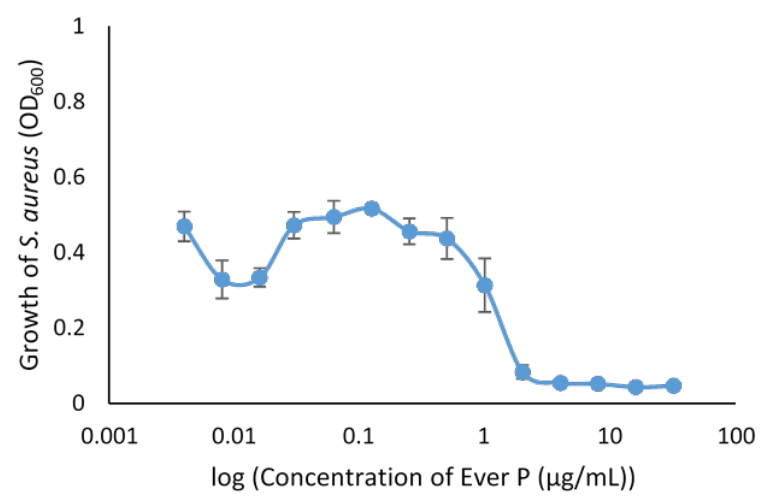

B Ever H Bioactivity

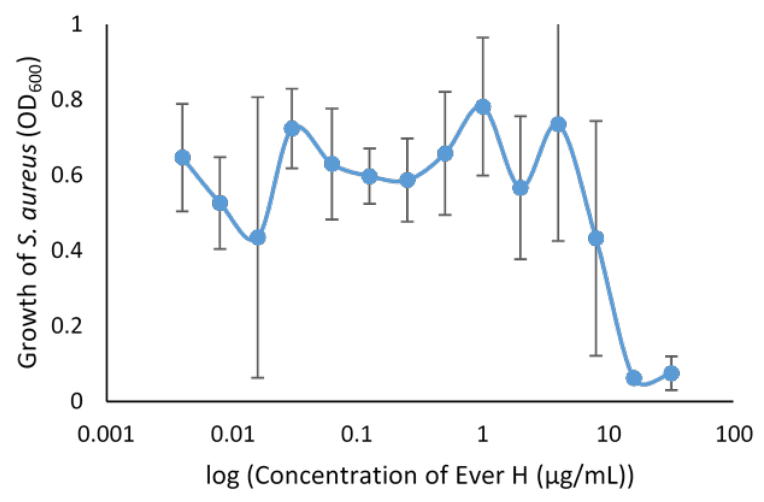

D Ever O Bioactivity

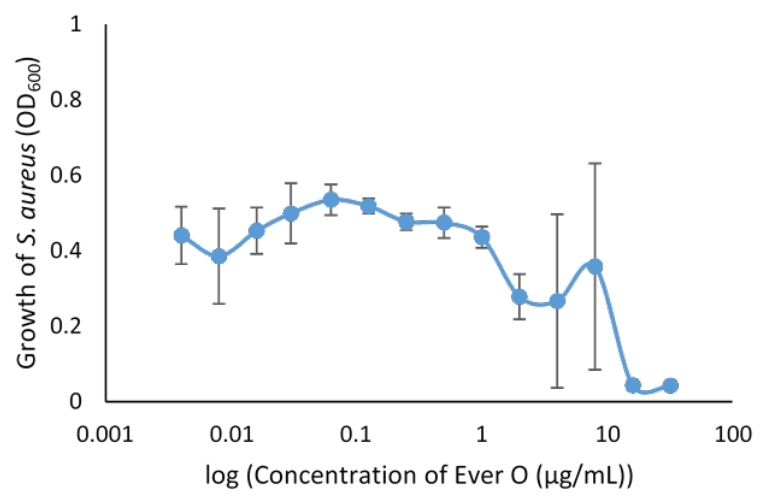


Figure S24. DMS-Map-Seq. MA plots of mutation counts vs log fold change in DMS reactivity for each rRNA nucleotide upon treatment with everninomicin $\mathrm{H}($ Evn $\mathrm{H}$ ), rosamicin (Rosa), or the everninomicinrosamicin conjugate (Evn P). Protected nucleotides passing statistical cutoffs are indicated in vermillion, and deprotected nucleotides in green. All labelled nucleotides are in the large subunit rRNA except for 16S A53.
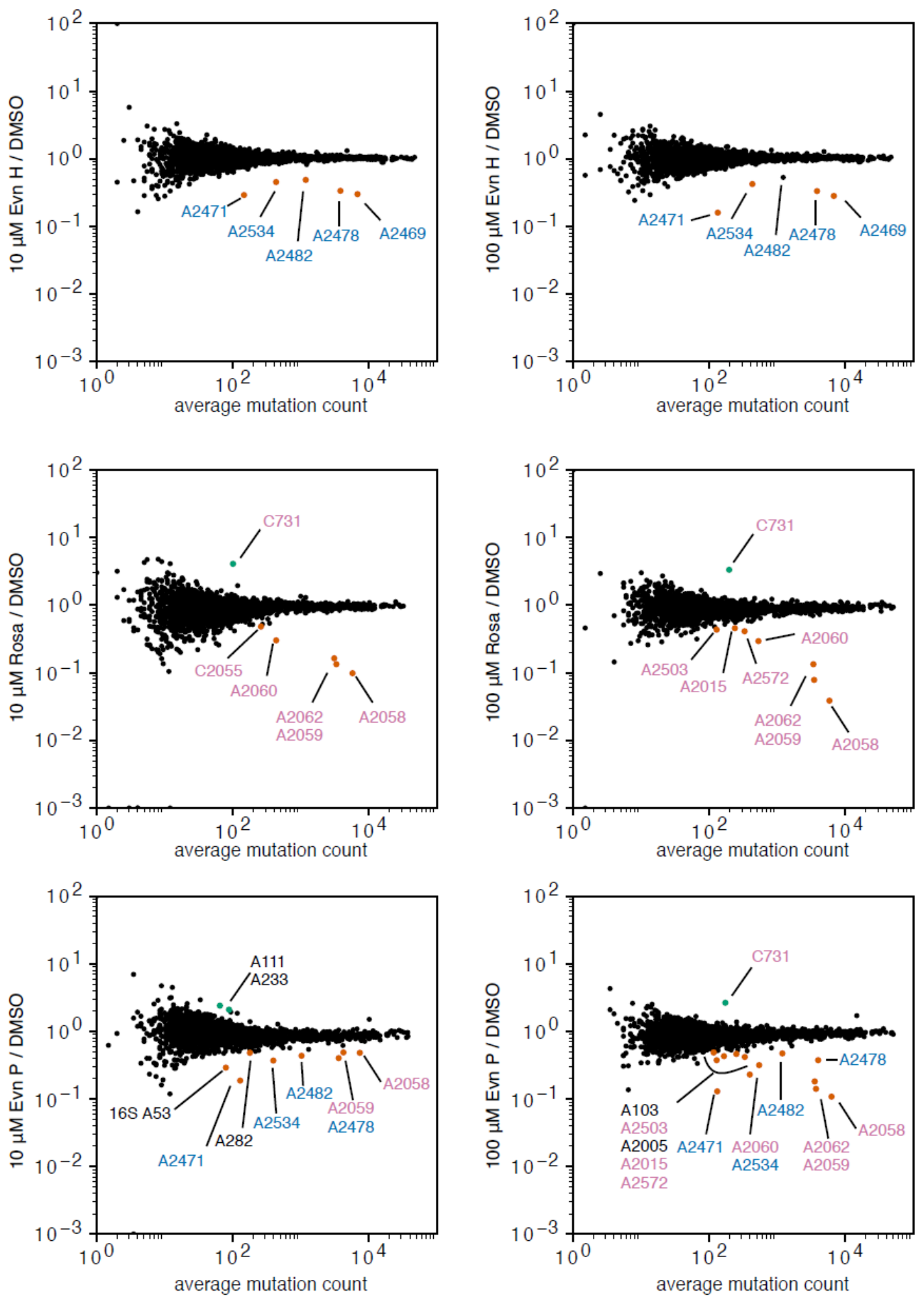
Table S1. Masses of everninomicins shown in Figures 3 and 4.

\begin{tabular}{|l|l|l|}
\hline Compound & Positive Mode (m/z) & Negative Mode (m/z) \\
\hline Evn D & $1536.5[\mathrm{M}+\mathrm{H}]^{+}$ & $1534.5[\mathrm{M}-\mathrm{H}]^{-}$ \\
\hline Evn E & $1506.5[\mathrm{M}+\mathrm{H}]^{+}$ & $1504.5[\mathrm{M}-\mathrm{H}]^{-}$ \\
\hline Evn F & $1522.5[\mathrm{M}+\mathrm{H}]^{+}$ & $1520.5[\mathrm{M}-\mathrm{H}]^{-}$ \\
\hline Evn G & $1520.5[\mathrm{M}+\mathrm{H}]^{+}$ & $1518.5[\mathrm{M}-\mathrm{H}]^{-}$ \\
\hline Evn M & $1349.5[\mathrm{M}+\mathrm{H}]^{+}$ & $1347.5[\mathrm{M}-\mathrm{H}]^{-}$ \\
\hline Evn N/O & $1263.5[\mathrm{M}+\mathrm{H}]^{+}$ & $1261.5[\mathrm{M}-\mathrm{H}]^{-}$ \\
\hline Evn P & $2086.5[\mathrm{M}+\mathrm{H}]^{+}$ & $2084.5[\mathrm{M}-\mathrm{H}]^{-}$ \\
\hline
\end{tabular}


Table S2. Evn N NMR data.

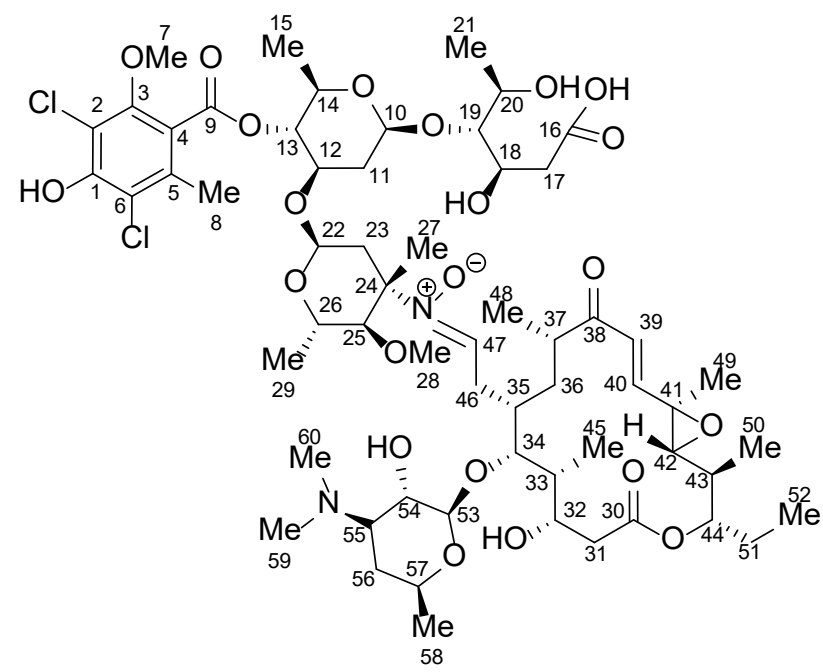

\begin{tabular}{|c|c|c|c|c|}
\hline Pos. & ${ }^{13} \mathrm{C}$ & ${ }^{1} \mathrm{H}$ & HMBC & NOESY \\
\hline 1 & 155.7 & & & \\
\hline 2 & 114.6 & & & \\
\hline 3 & 153.9 & & & \\
\hline 4 & 117.8 & & & \\
\hline 5 & 134.2 & & & \\
\hline 6 & 119.7 & & & \\
\hline 7 & 61.1 & $3.88,3 \mathrm{H}, \mathrm{s}$ & 3 & \\
\hline 8 & 17.4 & $2.36,3 \mathrm{H}, \mathrm{s}$ & $2,3,4,5,6$ & \\
\hline 9 & 166.7 & & & \\
\hline 10 & 100.0 & $4.72,1 \mathrm{H}, \mathrm{dd}(9.4,10.8 \mathrm{~Hz})$ & 11,19 & $11,12,14,19$ \\
\hline \multirow[t]{2}{*}{11} & 36.1 & $1.63,1 \mathrm{H}, \mathrm{m}$ & 10,12 & \\
\hline & & $2.45,1 \mathrm{H}, \mathrm{ddd}(3.8,5.3,11 \mathrm{~Hz})$ & $10,12,13$ & $10,12,22$ \\
\hline 12 & 72.7 & $3.97,1 \mathrm{H}$, overlap & 13,22 & $10,11,14,22$ \\
\hline 13 & 75.9 & $4.81,1 \mathrm{H}$, overlap & $9,12,13,14,15$ & \\
\hline 14 & 70.7 & $3.59,1 \mathrm{H}$, overlap & $10,13,15$ & $10,12,15$ \\
\hline 15 & 17.3 & $1.35,3 \mathrm{H}, \mathrm{d}(6.4 \mathrm{~Hz})$ & 13,14 & \\
\hline 16 & 176.8 & & & \\
\hline 17 & 39.3 & $2.56,2 \mathrm{H}$, broad & 16,18 & \\
\hline 18 & 68.0 & $4.25,1 \mathrm{H}$, broad & & 19 \\
\hline 19 & 84.0 & $3.53,1 \mathrm{H}$, overlap & 10 & 10 \\
\hline 20 & 67.2 & $3.95,1 \mathrm{H}$, overlap & & 19 \\
\hline 21 & 18.2 & $1.23,3 \mathrm{H}, \mathrm{d}(6.3 \mathrm{~Hz})$ & 19,20 & \\
\hline 22 & 93.2 & $5.05,1 \mathrm{H}, \mathrm{d}(4.8 \mathrm{~Hz})$ & $12,24,26$ & $11,12,23$ \\
\hline \multirow[t]{2}{*}{23} & 38.3 & $1.65,1 \mathrm{H}, \mathrm{dd}(1.9,2.8 \mathrm{~Hz})$ & $22,24,27$ & \\
\hline & & $2.86,1 \mathrm{H}$, overlap & $22,24,27$ & \\
\hline 24 & 73.9 & & & \\
\hline 25 & 82.3 & $3.58,1 \mathrm{H}$, overlap & 26,28 & 29 \\
\hline 26 & 65.4 & $3.59,1 \mathrm{H}$, overlap & 25 & 27 \\
\hline 27 & 18.9 & $1.65,3 \mathrm{H}, \mathrm{s}$ & $22,23,24,25$ & $22,23,26,47$ \\
\hline 28 & 60.1 & $3.28,3 \mathrm{H}, \mathrm{s}$ & 25 & 29 \\
\hline 29 & 16.7 & $0.79,3 \mathrm{H}, \mathrm{d}(5 \mathrm{~Hz})$ & 25,26 & \\
\hline 30 & 172.9 & & & \\
\hline \multirow[t]{2}{*}{31} & 39.4 & $2.25,1 \mathrm{H}, \mathrm{d}(16.8 \mathrm{~Hz})$ & 30,33 & \\
\hline & & $2.60,1 \mathrm{H}$ overlap & 30,32 & \\
\hline 32 & 66.3 & $3.83,1 \mathrm{H}$, broad $(10.2 \mathrm{~Hz})$ & $30,31,45$ & $31,34,35$ \\
\hline 33 & 40.8 & $1.91,1 \mathrm{H}$, overlap & 34,35 & \\
\hline 34 & 82.5 & $3.67,1 \mathrm{H}$, broad $(10 \mathrm{~Hz})$ & $33,35,36,45,46,53$ & $32,35,47,53$ \\
\hline 35 & 34.6 & $1.71,1 \mathrm{H}, \mathrm{m}$ & & \\
\hline 36 & 32.3 & $\begin{array}{l}1.51,1 \mathrm{H}, \text { overlap } \\
1.93,1 \mathrm{H}\end{array}$ & $\begin{array}{l}37,40 \\
37,46,48\end{array}$ & \\
\hline
\end{tabular}




\begin{tabular}{|c|c|c|c|c|}
\hline 37 & 45.4 & $2.64,1 \mathrm{H}$, overlap & 38 & \\
\hline Pos. & ${ }^{13} \mathrm{C}$ & ${ }^{1} \mathrm{H}$ & $\mathrm{HMBC}$ & NOESY \\
\hline 38 & 201.4 & & & \\
\hline 39 & 123.2 & $6.68,1 \mathrm{H}, \mathrm{d}(15.7 \mathrm{~Hz})$ & 38,41 & 48,49 \\
\hline 40 & 150.6 & $6.45,1 \mathrm{H}, \mathrm{d}(15.7 \mathrm{~Hz})$ & $38,39,42,49$ & 42 \\
\hline 41 & 59.6 & & & \\
\hline 42 & 68.2 & $2.84,1 \mathrm{H}, \mathrm{d}(9.6 \mathrm{~Hz})$ & $40,41,43,50$ & \\
\hline 43 & 37.6 & $1.74,1 \mathrm{H}, \mathrm{m}$ & $42,44,50$ & \\
\hline 44 & 76.8 & 4.86, $1 \mathrm{H}$, overlap & $30,43,51,52$ & \\
\hline 45 & 8.5 & $1.09,3 \mathrm{H}, \mathrm{d}(6.5 \mathrm{~Hz})$ & $32,33,34$ & \\
\hline \multirow[t]{2}{*}{46} & 30.0 & $2.51,1 \mathrm{H}$, overlap & & \\
\hline & & $2.88,1 \mathrm{H}$, overlap & 47 & \\
\hline 47 & 142.1 & $7.36,1 \mathrm{H}$, broad & 46 & 27,34 \\
\hline 48 & 16.3 & $1.17,3 \mathrm{H}, \mathrm{d}(7 \mathrm{~Hz})$ & $36,37,38$ & \\
\hline 49 & 13.9 & $1.46,3 \mathrm{H}, \mathrm{s}$ & $40,41,42$ & 39,43 \\
\hline 50 & 13.2 & $1.12,3 \mathrm{H}, \mathrm{d}(6.7 \mathrm{~Hz})$ & $42,43,44$ & \\
\hline \multirow[t]{2}{*}{51} & 24.2 & $1.54,1 \mathrm{H}$, overlap & $43,44,52$ & \\
\hline & & $1.83,1 \mathrm{H}, \mathrm{m}$ & 43,52 & \\
\hline 52 & 8.05 & $0.91,3 \mathrm{H}, \mathrm{t}(7.3 \mathrm{~Hz})$ & 44,51 & \\
\hline 53 & 103.5 & $4.32,1 \mathrm{H}, \mathrm{d}(7.2 \mathrm{~Hz})$ & 34,55 & 34,57 \\
\hline 54 & 69.1 & $3.41,1 \mathrm{H}, \mathrm{dd}(7.2,10.5 \mathrm{~Hz})$ & 53,55 & 59 or 60 \\
\hline 55 & 65.3 & 3.30, $1 \mathrm{H}$, overlap & 54 & 57 \\
\hline 56 & 29.8 & $\begin{array}{l}1.43,1 \mathrm{H} \text {, overlap } \\
1.92,1 \mathrm{H}\end{array}$ & 57,58 & \\
\hline 57 & 68.1 & $3.57,1 \mathrm{H}$, overlap & 59,61 & 53 \\
\hline 58 & 19.9 & $1.19,3 \mathrm{H}, \mathrm{d}(6.2 \mathrm{~Hz})$ & 56,57 & \\
\hline 59 & 38.7 & $2.77,3 \mathrm{H}, \mathrm{s}$ & 55,60 & \\
\hline 60 & 38.7 & $2.77,3 \mathrm{H}, \mathrm{s}$ & 55,59 & \\
\hline
\end{tabular}


Table S3. Evn O NMR data

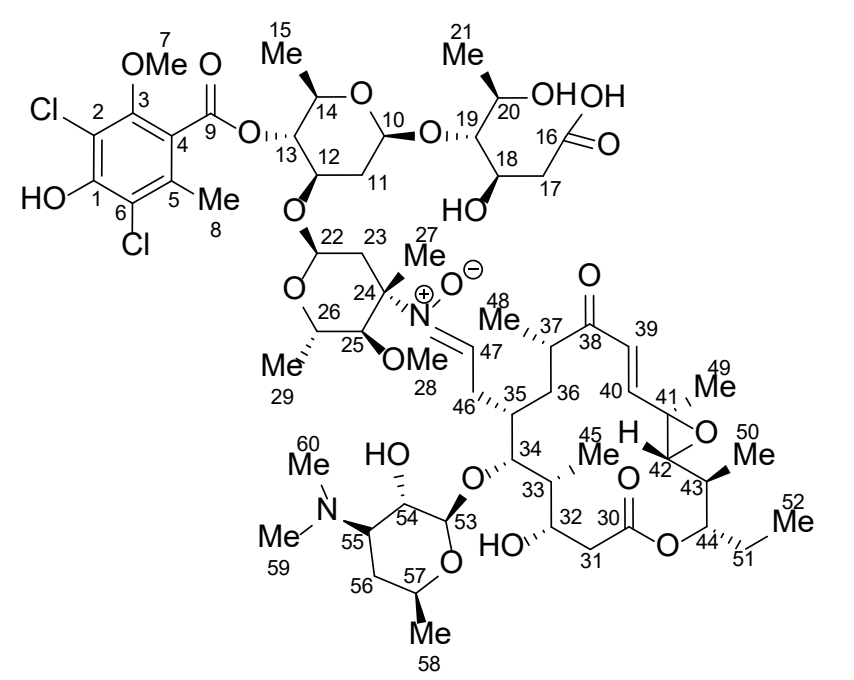

\begin{tabular}{|c|c|c|c|c|}
\hline Pos. & ${ }^{13} \mathrm{C}$ & ${ }^{1} \mathrm{H}$ & HMBC & NOESY \\
\hline 1 & 154.4 & & & \\
\hline 2 & $?$ & & & \\
\hline 3 & 154.1 & & & \\
\hline 4 & 113.8 & & & \\
\hline 5 & 133.6 & & & \\
\hline 6 & 121.3 & & & \\
\hline 7 & 60.7 & $3.87,3 \mathrm{H}, \mathrm{s}$ & 3 & \\
\hline 8 & 17.6 & $2.34,3 \mathrm{H}, \mathrm{s}$ & $2,3,4,5,6$ & \\
\hline 9 & 167.4 & & & \\
\hline 10 & 99.9 & $4.72,1 \mathrm{H}, \mathrm{dd}(9.4,10.8 \mathrm{~Hz})$ & 11,19 & $11,12,14,19$ \\
\hline \multirow[t]{2}{*}{11} & 36.3 & $1.62,1 \mathrm{H}, \mathrm{m}$ & 10,12 & \\
\hline & & $2.45,1 \mathrm{H}, \mathrm{ddd}(3.8,5.3,11 \mathrm{~Hz})$ & $10,12,13$ & $10,12,22$ \\
\hline 12 & 72.7 & $3.97,1 \mathrm{H}$, overlap & 13,22 & $10,11,14,22$ \\
\hline 13 & 75.4 & $4.81,1 \mathrm{H}$, overlap & $9,12,13,14,15$ & \\
\hline 14 & 70.6 & $3.59,1 \mathrm{H}$, overlap & $10,13,15$ & $10,12,15$ \\
\hline 15 & 17.3 & $1.35,3 \mathrm{H}, \mathrm{d}(6.4 \mathrm{~Hz})$ & 13,14 & \\
\hline 16 & 178.4 & & & \\
\hline 17 & 40.3 & $2.48,2 \mathrm{H}$, broad & 16,18 & \\
\hline 18 & 68.5 & $4.20,1 \mathrm{H}$, broad & & 19 \\
\hline 19 & 84.2 & $3.53,1 \mathrm{H}$, overlap & 10 & 10 \\
\hline 20 & 67.3 & $3.95,1 \mathrm{H}$, overlap & & 19 \\
\hline 21 & 17.9 & $1.23,3 \mathrm{H}, \mathrm{d}(6.3 \mathrm{~Hz})$ & 19,20 & \\
\hline 22 & 93.0 & $5.05,1 \mathrm{H}, \mathrm{d}(4.8 \mathrm{~Hz})$ & $12,24,26$ & $11,12,23$ \\
\hline \multirow[t]{2}{*}{23} & 38.4 & $1.65,1 \mathrm{H}, \mathrm{dd}(1.9,2.8 \mathrm{~Hz})$ & $22,24,27$ & \\
\hline & & $2.86,1 \mathrm{H}$, overlap & $22,24,27$ & \\
\hline 24 & 74.1 & & & \\
\hline 25 & 82.3 & $3.58,1 \mathrm{H}$, overlap & 26,28 & 29 \\
\hline 26 & 65.5 & $3.62,1 \mathrm{H}$, overlap & 25 & 27 \\
\hline 27 & 19.0 & $1.65,3 \mathrm{H}, \mathrm{s}$ & $22,23,24,25$ & $22,23,26,47$ \\
\hline 28 & 60.0 & $3.28,3 \mathrm{H}, \mathrm{s}$ & 25 & 29 \\
\hline 29 & 16.8 & $0.82,3 \mathrm{H}, \mathrm{d}(5 \mathrm{~Hz})$ & 25,26 & \\
\hline 30 & 172.9 & & & \\
\hline \multirow[t]{2}{*}{31} & 39.4 & $2.25,1 \mathrm{H}, \mathrm{d}(16.8 \mathrm{~Hz})$ & 30,33 & \\
\hline & & $2.60,1 \mathrm{H}$ overlap & 30,32 & \\
\hline 32 & 66.3 & $3.83,1 \mathrm{H}$, broad $(10.2 \mathrm{~Hz})$ & $30,31,45$ & $31,34,35$ \\
\hline 33 & 40.8 & $1.91,1 \mathrm{H}$, overlap & 34,35 & \\
\hline 34 & 82.2 & $3.68,1 \mathrm{H}$, broad $(10 \mathrm{~Hz})$ & $33,35,36,45,46,53$ & $32,35,47,53$ \\
\hline 35 & $?$ & $?$ & & \\
\hline 36 & 32.0 & $\begin{array}{l}1.49,1 \mathrm{H}, \text { overlap } \\
1.93,1 \mathrm{H}\end{array}$ & $\begin{array}{l}37,40 \\
37,46,48\end{array}$ & \\
\hline
\end{tabular}




\begin{tabular}{|c|c|c|c|c|}
\hline $\begin{array}{l}37 \\
38\end{array}$ & $\begin{array}{l}45.4 \\
201.6\end{array}$ & $2.64,1 \mathrm{H}$, overlap & 38 & \\
\hline Pos. & ${ }^{13} \mathrm{C}$ & ${ }^{1} \mathrm{H}$ & HMBC & NOESY \\
\hline 39 & 123.3 & $6.68,1 \mathrm{H}, \mathrm{d}(15.7 \mathrm{~Hz})$ & 38,41 & 48,49 \\
\hline 40 & 150.6 & $6.45,1 \mathrm{H}, \mathrm{d}(15.7 \mathrm{~Hz})$ & $38,39,42,49$ & 42 \\
\hline 41 & 59.7 & & & \\
\hline 42 & 68.1 & $2.84,1 \mathrm{H}, \mathrm{d}(9.6 \mathrm{~Hz})$ & $40,41,43,50$ & \\
\hline 43 & 37.6 & $1.74,1 \mathrm{H}, \mathrm{m}$ & $42,44,50$ & \\
\hline 44 & 76.6 & $4.86,1 \mathrm{H}$, overlap & $30,43,51,52$ & \\
\hline 45 & 8.5 & $1.09,3 \mathrm{H}, \mathrm{d}(6.5 \mathrm{~Hz})$ & $32,33,34$ & \\
\hline \multirow[t]{2}{*}{46} & 29.6 & $2.49,1 \mathrm{H}$, overlap & & \\
\hline & & 2.94, $1 \mathrm{H}$, overlap & 47 & \\
\hline 47 & 142.0 & $7.42,1 \mathrm{H}$, broad & 46 & 27,34 \\
\hline 48 & 16.3 & $1.17,3 \mathrm{H}, \mathrm{d}(7 \mathrm{~Hz})$ & $36,37,38$ & \\
\hline 49 & 13.9 & $1.46,3 \mathrm{H}, \mathrm{s}$ & $40,41,42$ & 39,43 \\
\hline 50 & 13.2 & $1.12,3 \mathrm{H}, \mathrm{d}(6.7 \mathrm{~Hz})$ & $42,43,44$ & \\
\hline \multirow[t]{2}{*}{51} & 24.2 & $1.54,1 \mathrm{H}$, overlap & $43,44,52$ & \\
\hline & & $1.83,1 \mathrm{H}, \mathrm{m}$ & 43,52 & \\
\hline 52 & 8.1 & $0.90,3 \mathrm{H}, \mathrm{t}(7.3 \mathrm{~Hz})$ & 44,51 & \\
\hline 53 & 103.7 & $4.30,1 \mathrm{H}, \mathrm{d}(7.2 \mathrm{~Hz})$ & 34,55 & 34,57 \\
\hline 54 & 69.9 & $3.32,1 \mathrm{H}, \mathrm{dd}(7.2,10.5 \mathrm{~Hz})$ & 53,55 & 59 or 60 \\
\hline 55 & 64.9 & 3.01, 1H, overlap & 54 & 57 \\
\hline 56 & 30.0 & $\begin{array}{l}1.32,1 \mathrm{H} \text {, overlap } \\
1.82,1 \mathrm{H}\end{array}$ & 57,58 & \\
\hline 57 & 68.4 & $3.50,1 \mathrm{H}$, overlap & 59,61 & 53 \\
\hline 58 & 20.0 & $1.17,3 \mathrm{H}, \mathrm{d}(6.2 \mathrm{~Hz})$ & 56,57 & \\
\hline 59 & 38.7 & $2.59,3 \mathrm{H}, \mathrm{s}$ & 55,60 & \\
\hline 60 & 38.7 & $2.59,3 \mathrm{H}, \mathrm{s}$ & 55,59 & \\
\hline
\end{tabular}


Table S4. Evn P NMR data.

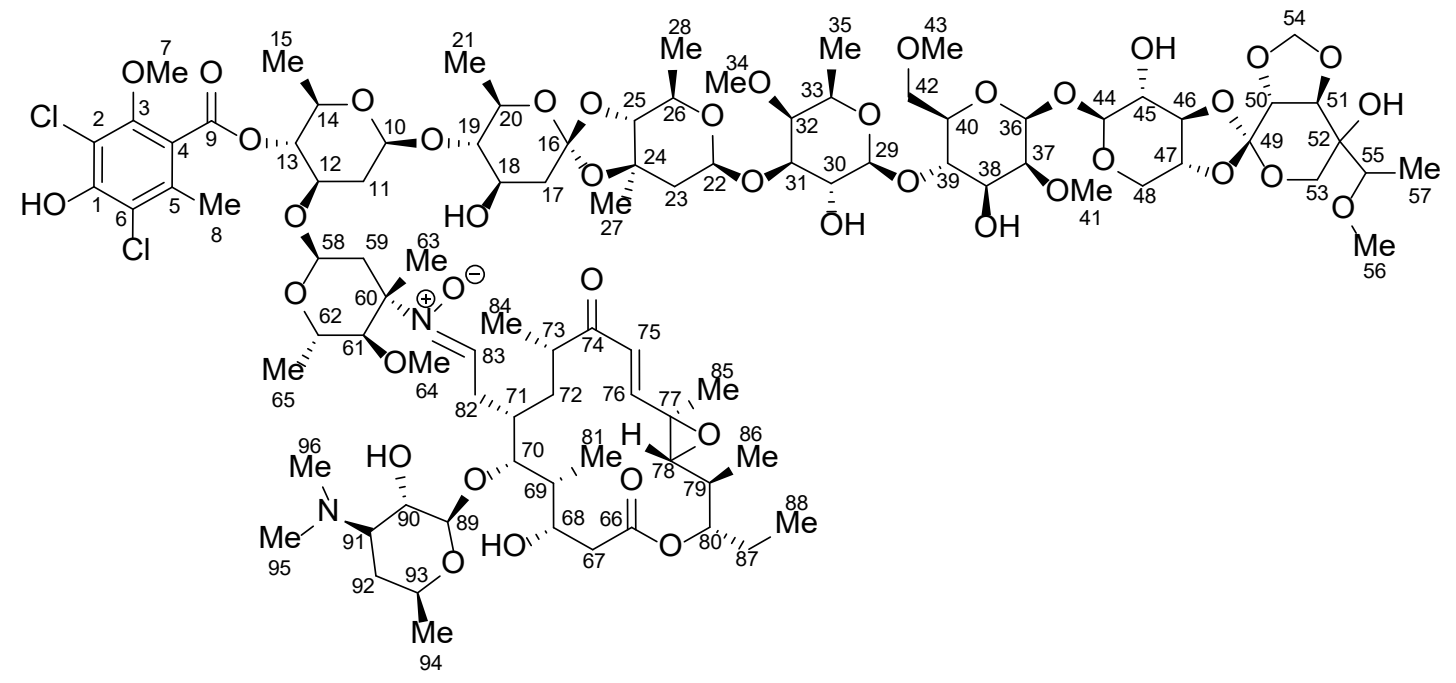

\begin{tabular}{|c|c|c|c|}
\hline Pos. & ${ }^{13} \mathrm{C}$ & ${ }^{1} \mathrm{H}$ & HMBC \\
\hline 1 & $?$ & & \\
\hline 2 & 113.3 & & \\
\hline 3 & 154.0 & & \\
\hline 4 & $?$ & & \\
\hline 5 & 133.7 & & \\
\hline 6 & 121.1 & & \\
\hline 7 & 60.7 & $3.87,3 \mathrm{H}, \mathrm{s}$ & 3 \\
\hline 8 & 17.5 & $2.34,3 \mathrm{H}, \mathrm{s}$ & $4,5,6$ \\
\hline 9 & 166.8 & & \\
\hline 10 & 100.3 & $4.73,1 \mathrm{H}, \mathrm{dd}(9.4,10.8 \mathrm{~Hz})$ & 11,19 \\
\hline \multirow[t]{2}{*}{11} & 36.2 & $1.66,1 \mathrm{H}, \mathrm{m}$ & 10,12 \\
\hline & & $2.45,1 \mathrm{H}, \mathrm{m}$ & 10,12 \\
\hline 12 & 72.3 & $4.01,1 \mathrm{H}, \mathrm{m}$ & $11,13,14$ \\
\hline 13 & 74.9 & $4.85,1 \mathrm{H}$, overlap & $9,12,14$ \\
\hline 14 & 70.8 & $3.71,1 \mathrm{H}$, overlap & 13,15 \\
\hline 15 & 17.2 & $1.35,3 \mathrm{H}$, overlap & 14 \\
\hline 16 & 120.2 & & \\
\hline \multirow[t]{2}{*}{17} & 39.9 & $1.73,1 \mathrm{H}$ & 16 \\
\hline & & $2.25,1 \mathrm{H}$ & $16,18,19$ \\
\hline 18 & 68.1 & 3.77, $1 \mathrm{H}$, overlap & 17,19 \\
\hline 19 & 86.8 & $3.14,1 \mathrm{H}, \mathrm{dd}(8.9,9.2 \mathrm{~Hz})$ & $10,18,20,21$ \\
\hline 20 & 70.0 & 3.77, $1 \mathrm{H}$, overlap & 19,21 \\
\hline 21 & 16.5 & $1.26,3 \mathrm{H}$, overlap & 19,20 \\
\hline 22 & 102.0 & $5.05,1 \mathrm{H}$, overlap & 23,31 \\
\hline \multirow[t]{2}{*}{23} & 43.2 & $1.78,1 \mathrm{H}, \mathrm{dd}(1.9,2.8 \mathrm{~Hz})$ & 24 \\
\hline & & $2.35,1 \mathrm{H}$, overlap & 22,24 \\
\hline 24 & 78.7 & & \\
\hline 25 & 85.0 & 3.34, $1 \mathrm{H}$, overlap & \\
\hline 26 & 68.1 & $3.83,1 \mathrm{H}$, overlap & 28 \\
\hline 27 & 18.7 & $1.36,3 \mathrm{H}, \mathrm{s}$ & $23,24,25$ \\
\hline 28 & 17.4 & $1.29,3 \mathrm{H}, \mathrm{d}(6.5 \mathrm{~Hz})$ & 25,26 \\
\hline 29 & 103.9 & $4.21,1 \mathrm{H}, \mathrm{d}(7.7 \mathrm{~Hz})$ & 30,39 \\
\hline 30 & 70.1 & $3.51,1 \mathrm{H}$, overlap & \\
\hline 31 & 82.7 & $3.59,1 \mathrm{H}$, overlap & 32 \\
\hline 32 & 81.4 & $3.51,1 \mathrm{H}, \operatorname{broad}(10.2 \mathrm{~Hz})$ & \\
\hline 33 & 70.5 & $3.71,1 \mathrm{H}$, overlap & 35 \\
\hline 34 & 60.7 & $3.57,3 \mathrm{H}, \mathrm{s}$ & 32 \\
\hline 35 & 15.1 & $1.26,3 \mathrm{H}$, overlap & 33 \\
\hline 36 & 95.9 & $4.82,1 \mathrm{H}$, overlap & 44 \\
\hline 37 & 79.6 & 41 & \\
\hline
\end{tabular}




\begin{tabular}{|c|c|c|c|}
\hline Pos. & ${ }^{13} \mathrm{C}$ & ${ }^{1} \mathrm{H}$ & HMBC \\
\hline 38 & $?$ & & \\
\hline 39 & 77.7 & $3.98,1 \mathrm{H}$, overlap & 29 \\
\hline 40 & ? & & \\
\hline 41 & 58.1 & $3.51,3 \mathrm{H}, \mathrm{s}$ & 37 \\
\hline 42 & 70.5 & $3.75,2 \mathrm{H}$, overlap & \\
\hline 43 & 57.9 & $3.38,3 \mathrm{H}, \mathrm{s}$ & 42 \\
\hline 44 & 94.9 & $5.25,1 \mathrm{H}, \mathrm{d}(1.4 \mathrm{~Hz})$ & 36,45 \\
\hline 45 & 72.5 & $3.97,1 \mathrm{H}$, overlap & 46 \\
\hline 46 & 80.6 & $3.95,1 \mathrm{H}, \mathrm{dd}(2.5,10.1 \mathrm{~Hz})$ & \\
\hline 47 & 69.1 & $4.26,1 \mathrm{H}, \mathrm{ddd}(4.4,10,15 \mathrm{~Hz})$ & \\
\hline \multirow[t]{2}{*}{48} & 62.9 & $3.80,1 \mathrm{H}$, overlap & 46,47 \\
\hline & & $4.07,1 \mathrm{H}, \mathrm{dd}(4.7,9.9 \mathrm{~Hz})$ & 46 \\
\hline 49 & 119.7 & & \\
\hline 50 & 72.8 & 3.87, $1 \mathrm{H}$, overlap & \\
\hline 51 & 76.8 & $3.87,1 \mathrm{H}$, overlap & \\
\hline 52 & 75.3 & & \\
\hline 53 & 69.1 & $\begin{array}{l}\text { 3.62, } 1 \mathrm{H} \text {, overlap } \\
3.92,1 \mathrm{H}, \mathrm{d}(12.2 \mathrm{~Hz})\end{array}$ & $49,51,52$ \\
\hline 54 & 95.4 & $\begin{array}{l}5.02,1 \mathrm{H}, \mathrm{s} \\
5.06,1 \mathrm{H}, \mathrm{s}\end{array}$ & 50 \\
\hline 55 & 79.5 & $3.31,1 \mathrm{H}, \mathrm{d}(6.2 \mathrm{~Hz})$ & 56 \\
\hline 56 & 56.3 & $3.34,3 \mathrm{H}, \mathrm{s}$ & 55 \\
\hline 57 & 12.5 & $1.25,3 \mathrm{H}$, overlap & 52,55 \\
\hline 58 & 93.1 & $5.06,1 \mathrm{H}$, overlap & 12,59 \\
\hline \multirow[t]{2}{*}{59} & 38.3 & $1.64,1 \mathrm{H}$, overlap & 60 \\
\hline & & $2.85,1 \mathrm{H}$, overlap & 60,63 \\
\hline 60 & 73.9 & & \\
\hline 61 & 82.3 & $3.57,1 \mathrm{H}$, overlap & 60,64 \\
\hline 62 & 65.5 & $3.63,1 \mathrm{H}$, overlap & 61,65 \\
\hline 63 & 19.1 & $1.65,3 \mathrm{H}, \mathrm{s}$ & $59,60,61$ \\
\hline 64 & 60.1 & $3.28,3 \mathrm{H}, \mathrm{s}$ & 61 \\
\hline 65 & 16.8 & $0.82,3 \mathrm{H}, \mathrm{d}(6 \mathrm{~Hz})$ & 61,62 \\
\hline 66 & 172.9 & & \\
\hline \multirow[t]{2}{*}{67} & 39.5 & $2.27,1 \mathrm{H}$, overlap & 66 \\
\hline & & $2.61,1 \mathrm{H}$, overlap & 66 \\
\hline 68 & 66.5 & $3.81,1 \mathrm{H}$, overlap & \\
\hline 69 & 40.9 & 1.91, $1 \mathrm{H}$, overlap & \\
\hline 70 & 82.3 & $3.69,1 \mathrm{H}$, overlap & 89 \\
\hline 71 & 34.6 & 1.72. $1 \mathrm{H}$, overlap & \\
\hline \multirow[t]{2}{*}{72} & 32.1 & $1.50,1 \mathrm{H}$, overlap & \\
\hline & & $1.93,1 \mathrm{H}$, overlap & \\
\hline 73 & 45.4 & $2.64,1 \mathrm{H}$, overlap & 84 \\
\hline 74 & 201.6 & & \\
\hline 75 & 123.3 & $6.69,1 \mathrm{H}, \mathrm{d}(16 \mathrm{~Hz})$ & 74,76 \\
\hline 76 & 150.6 & $6.42,1 \mathrm{H}, \mathrm{d}(16 \mathrm{~Hz})$ & 75,77 \\
\hline 77 & 59.8 & & \\
\hline 78 & 68.2 & $2.85,1 \mathrm{H}$, overlap & 76,79 \\
\hline 79 & 37.6 & $1.75,1 \mathrm{H}$, overlap & 86 \\
\hline 80 & 76.7 & $4.85,1 \mathrm{H}$, overlap & 79,87 \\
\hline 81 & 8.4 & $1.09,3 \mathrm{H}, \mathrm{d}(6.6 \mathrm{~Hz})$ & \\
\hline \multirow[t]{2}{*}{82} & 29.8 & $2.50,1 \mathrm{H}$, overlap & \\
\hline & & $2.91,1 \mathrm{H}, \mathrm{m}$ & \\
\hline 83 & 142.2 & $7.40,1 \mathrm{H}$, broad & \\
\hline 84 & 16.3 & $1.17,3 \mathrm{H}$, overlap & $72,73,74$ \\
\hline 85 & 13.9 & $1.46,3 \mathrm{H}$, overlap & $76,77,78$ \\
\hline 86 & 13.2 & $1.11,3 \mathrm{H}, \mathrm{d}(6.8 \mathrm{~Hz})$ & $78,79,80$ \\
\hline \multirow[t]{2}{*}{87} & 24.2 & $1.54,1 \mathrm{H}, \mathrm{m}$ & 80 \\
\hline & & $1.82,1 \mathrm{H}$, overlap & \\
\hline 88 & 8.1 & $0.91,3 \mathrm{H}, \mathrm{t}(7.4 \mathrm{~Hz})$ & 80,87 \\
\hline 89 & 103.8 & $4.30,1 \mathrm{H}, \mathrm{d}(7.1 \mathrm{~Hz})$ & 70 \\
\hline 90 & 69.9 & 3.32, $1 \mathrm{H}$, overlap & \\
\hline 91 & 64.9 & $3.00,1 \mathrm{H}, \mathrm{m}$ & 95,96 \\
\hline \multirow[t]{2}{*}{92} & 30.0 & 1.32. $1 \mathrm{H}$, overlap & \\
\hline & & $1.81,1 \mathrm{H}$, overlap & \\
\hline 93 & 68.5 & 3.49. $1 \mathrm{H}$, overlap & 94 \\
\hline 94 & 20.1 & 1.16, $3 \mathrm{H}$, overlap & 93 \\
\hline 95 & 38.9 & $2.58,3 \mathrm{H}, \mathrm{s}$ & 91 \\
\hline 96 & 38.9 & $2.62,3 \mathrm{H}, \mathrm{s}$ & 91 \\
\hline
\end{tabular}


Table S5. Strains and plasmids used in this study.

\begin{tabular}{|c|c|c|}
\hline Strain/plasmid & Relevant genotype/comments & Source/reference \\
\hline \multicolumn{3}{|l|}{ E. coli } \\
\hline TOP10 & General cloning purposes & Invitrogen \\
\hline BW25113 & $\mathrm{K} 12$ derivative: $\triangle \mathrm{ara} B A D, \triangle r h a B A D$ & 33 \\
\hline ET12567 & $\begin{array}{l}\text { Non-methylating E. coli host used for conjugation: dam, } \\
d c m, h s d S \text {, cat, tet }\end{array}$ & 34 \\
\hline \multicolumn{3}{|l|}{ M. carbonacea var aurantiaca } \\
\hline Wild-type & Everninomicin producer & NRRL 2997 \\
\hline$\Delta e v d N 1:: a a c(3) I V$ & Gene replacement of evdN1, apramycin resistance & This study \\
\hline$\Delta$ evdO1::aac(3)IV & Gene replacement of evdO1, apramycin resistance & McCulloch et al., 2015 \\
\hline$\Delta e v d 01:: a a c(3) I V+e v d 01$ & $\begin{array}{l}\text { Genetic complementation of } \triangle \text { evdO1::aac(3)IV with } \\
\text { pSET152ermE+evdO1 }\end{array}$ & This study \\
\hline$\Delta e v d N 1:: a a c(3) I V+e v d N 1$ & $\begin{array}{l}\text { Genetic complementation of } \Delta \text { evdO1::aac(3)IV with } \\
\text { pSET152ermE+evdN1 }\end{array}$ & This study \\
\hline \multicolumn{3}{|l|}{ Plasmids and Cosmids } \\
\hline plJ790 & $\lambda$-RED (gam, bet, exo), cat, araC, rep101"s & 1 \\
\hline plJ773 & aac(3)IV, oriT & 1 \\
\hline $\mathrm{CA}$ & Cosmid containing part of evd gene cluster: neo, bla & Ecopia BioSciences Inc. \\
\hline CG & Cosmid containing part of evd gene cluster: neo, bla & Ecopia BioSciences Inc. \\
\hline pSET152 & 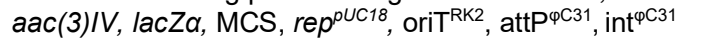 & \\
\hline pSET152ermE & pSET152 derivative containing ermE* upstream of MCS & This study \\
\hline pSET152ermE+evdN1 & pSET152ermE* derivative containing evdN1 & This study \\
\hline pSET152ermE+evdO1 & pSET152ermE* derivative containing evdO1 & This study \\
\hline
\end{tabular}

Table S6. Primers used in this study.

\begin{tabular}{|c|c|c|}
\hline Primer Name & Used for & Sequence (5'-3') \\
\hline RED-N1-For & $\Delta e v d N 1:: a a c(3) I V$ & ATGGTCGACCTGCTGACCGGCGTACTCCCGCAGATCCGGATTCCGGGGATCCGTCGACC \\
\hline RED-N1-Rev & $\triangle e v d N 1:: a a c(3) I V$ & ATTCCGGCAGGTAGTCCCACACTCGGATGGTCATGTTCATGTAGGCTGGAGCTGCTTC \\
\hline $\begin{array}{l}\text { EvdN1- } \\
\text { Southern-For }\end{array}$ & $\begin{array}{l}\text { EvdN1 Southern } \\
\text { Probe }\end{array}$ & ACGACGAGCACTTCTTCCTG \\
\hline EvdN1- & EvdN1 Southern & GAAGACCGAGTCCAGGTACG \\
\hline Southern-Rev & Probe & \\
\hline $\begin{array}{l}\text { Apr-Southern- } \\
\text { For }\end{array}$ & $\begin{array}{c}\text { Apramycin Southern } \\
\text { Probe }\end{array}$ & ACCGACTGGACCTTCCTTCT \\
\hline $\begin{array}{l}\text { Apr-Southern- } \\
\text { Rev }\end{array}$ & $\begin{array}{c}\text { Apramycin Southern } \\
\text { Probe }\end{array}$ & TCGCTATAATGACCCCGAAG \\
\hline EvdN1-GC-For & $\begin{array}{c}\text { pSET152ermE*- } \\
\text { evdN1 }\end{array}$ & CATATGAGCGAATTCATGGTCGACCTG \\
\hline $\begin{array}{l}\text { EvdN1-GC- } \\
\text { Rev }\end{array}$ & $\begin{array}{l}\text { pSET152ermE*- } \\
\text { evdN1 }\end{array}$ & GATATCCACTCGGATGGTCATGTTCA \\
\hline $\begin{array}{l}\text { HygBCheck- } \\
\text { For }\end{array}$ & Confirm GC vectors & GATTCGGATGATTCCTACGC \\
\hline $\begin{array}{l}\text { HygBCheck- } \\
\text { Rev }\end{array}$ & Confirm GC vectors & GAAGGCGTTGAGATGCAGTT \\
\hline Del-Up & $\begin{array}{l}\text { Confirm gene } \\
\text { replacements }\end{array}$ & ATTCCGGGGATCCGTCGACC \\
\hline Del-Dn & $\begin{array}{l}\text { Confirm gene } \\
\text { replacements }\end{array}$ & TGTAGGCTGGAGCTGCTTC \\
\hline
\end{tabular}


Table S7. Summary of genome assemblies for $M$. Carbonacea strains.

\begin{tabular}{|c|c|c|}
\hline & M. carbonacea var. auriantiaca & M. carbonacea var. africana \\
\hline Genbank accession & CP058322 & $\begin{array}{l}\text { CP058905 } \\
\text { CP058906 } \\
\end{array}$ \\
\hline number of contigs & 1 & 2 \\
\hline total length $(\mathrm{bp}$ & $7,528,329$ & $6,830,161$ \\
\hline shortest contig & $7,528,329$ & 43,352 \\
\hline largest contig & $7,528,329$ & $6,786,809$ \\
\hline average coverage (Illumina) & 183 & 146 \\
\hline N50 (bp) & $7,528,329$ & $6,786,809$ \\
\hline $\mathrm{N} 75(\mathrm{bp})$ & $7,528,329$ & $6,786,809$ \\
\hline \multicolumn{3}{|l|}{ BUSCO marker genes (392) } \\
\hline Complete & 352 & 350 \\
\hline Complete and single-copy & 347 & 346 \\
\hline Complete and duplicated & 5 & 4 \\
\hline Fragmented & 1 & 2 \\
\hline Missing & 3 & 4 \\
\hline \multicolumn{3}{|l|}{ PGAP annotations } \\
\hline Genes & 6,352 & 5,936 \\
\hline CDSs & 6,286 & 5,870 \\
\hline Pseudo genes & 150 & 260 \\
\hline RNAs & 66 & 66 \\
\hline Everninomicin locus & $866,393-925,867$ & $835,716-887,304$ \\
\hline Rosamicin locus & $1,361,829-1,422,030$ & NA \\
\hline
\end{tabular}


Figure S25. Biosynthetic gene cluster for rosamicin in M. carbonacea var. aurantiaca. Potential operonal units are minimally defined by transcriptional gene directionality, which is indicated by green (sense) and red (antisense), respectively. (GenBank Nucleotide Accession: CP058322.1, genome region $1361829-1422030)$

rosamicin

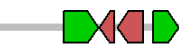

1360000

1380000

1400000

1420000

Figure S26. HPLC/MS analysis of a crude extract of $M$. carbonacea var. aurantiaca under conditions for production of Evn P. Extracted ion currents are shown for rosamicin aldehyde $(\mathrm{m} / \mathrm{z}=$ $\left.582.2[\mathrm{M}+\mathrm{H}]^{+} ; \mathrm{m} / \mathrm{z}=580.2[\mathrm{M}-\mathrm{H}]^{-}\right)$, Evn $\mathrm{F}$ hydroxylamine $\left(\mathrm{m} / \mathrm{z}=1522.7[\mathrm{M}+\mathrm{H}]^{+} ; \mathrm{m} / \mathrm{z}=1520.7[\mathrm{M}-\mathrm{H}]^{-}\right)$, and Evn P nitrone $\left(\mathrm{m} / \mathrm{z}=2086.5[\mathrm{M}+\mathrm{H}]^{+} ; \mathrm{m} / \mathrm{z}=2084.5[\mathrm{M}-\mathrm{H}]^{-}\right)$, demonstrating presence of these metabolites in late stage production cultures. The chromatogram shows summed ion intensities in negative mode (orange) and positive mode (black).

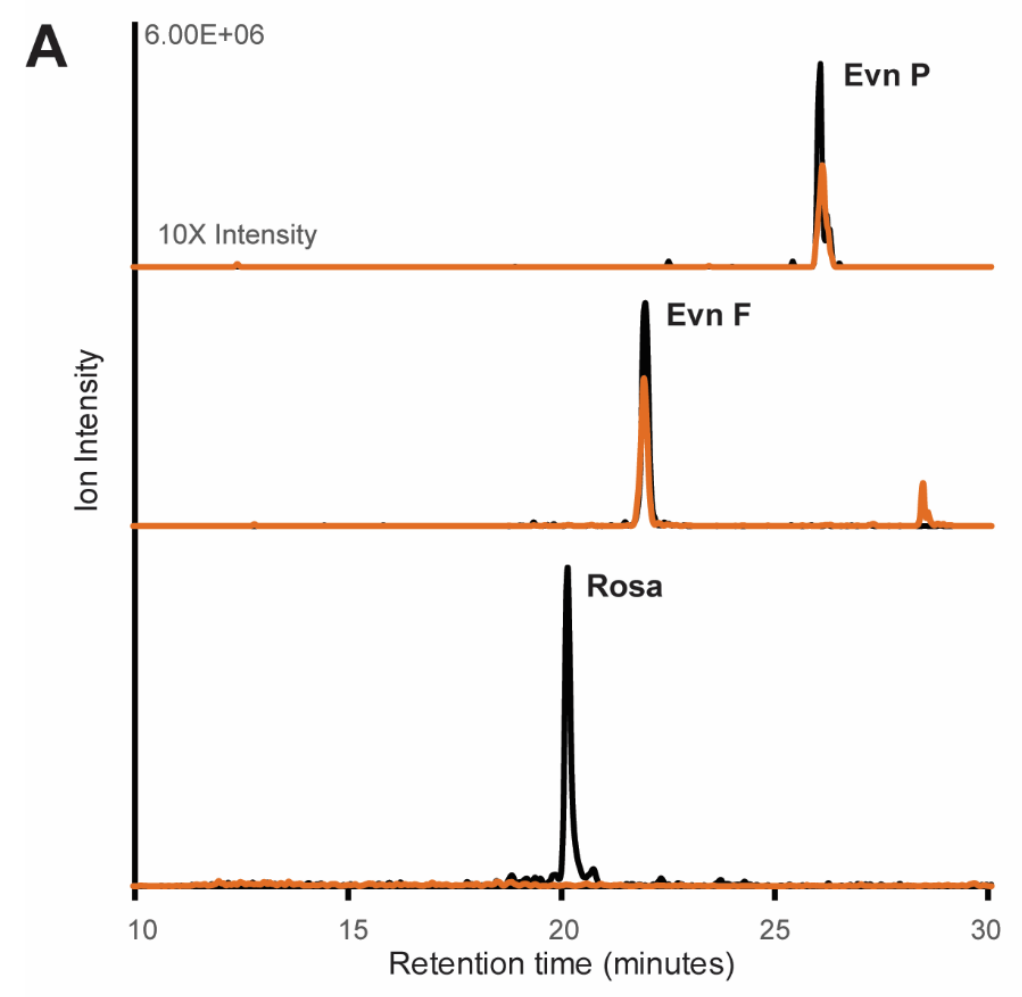




\section{References}

1. Gust, B.; Challis, G. L.; Fowler, K.; Kieser, T.; Chater, K. F., PCR-targeted Streptomyces gene replacement identifies a protein domain needed for biosynthesis of the sesquiterpene soil odor geosmin. Proc Natl Acad Sci U S A 2003, 100 (4), 1541-6.

2. Gust, B.; Chandra, G.; Jakimowicz, D.; Yuqing, T.; Bruton, C. J.; Chater, K. F., Lambda redmediated genetic manipulation of antibiotic-producing Streptomyces. Adv Appl Microbiol 2004, 54, 10728.

3. Limbrick, E. M.; Yñigez-Gutierrez, A. E.; Dulin, C. C.; Derewacz, K. D.; Spraggins, J. M.; McCulloch, K. M.; Iverson, T. M.; Bachmann, B. O., Methyltransferase contingencies in the pathway of everninomicin $\mathrm{D}$ antibiotics and analogs. Submitted 2020.

4. Marshall, A. G.; Hendrickson, C. L.; Jackson, G. S., Fourier transform ion cyclotron resonance mass spectrometry: a primer. Mass Spectrom Rev 1998, 17 (1), 1-35.

5. Herrmann, K. A.; Somogyi, A.; Wysocki, V. H.; Drahos, L.; Vekey, K., Combination of sustained off-resonance irradiation and on-resonance excitation in FT-ICR. Anal Chem 2005, 77 (23), 7626-38.

6. Kieser, T.; Foundation, J. I., Practical Streptomyces Genetics. John Innes Foundation: 2000.

7. Kolmogorov, M.; Yuan, J.; Lin, Y.; Pevzner, P. A., Assembly of long, error-prone reads using repeat graphs. Nature Biotechnology 2019, 37 (5), 540-546.

8. Walker, B. J.; Abeel, T.; Shea, T.; Priest, M.; Abouelliel, A.; Sakthikumar, S.; Cuomo, C. A.; Zeng, Q.; Wortman, J.; Young, S. K.; Earl, A. M., Pilon: An Integrated Tool for Comprehensive Microbial Variant Detection and Genome Assembly Improvement. PloS One 2014, 9 (11), e112963.

9. Wick, R. R.; Judd, L. M.; Gorrie, C. L.; Holt, K. E., Unicycler: Resolving bacterial genome assemblies from short and long sequencing reads. PLOS Computational Biology 2017, 13 (6), e1005595.

10. Blin, K.; Shaw, S.; Steinke, K.; Villebro, R.; Ziemert, N.; Lee, S. Y.; Medema, M. H.; Weber, T., antiSMASH 5.0: updates to the secondary metabolite genome mining pipeline. Nucleic acids research 2019, 47 (W1), W81-W87.

11. Seppey, M.; Manni, M.; Zdobnov, E. M., BUSCO: Assessing Genome Assembly and Annotation Completeness. In Gene Prediction: Methods and Protocols, Kollmar, M., Ed. Springer New York: New York, NY, 2019; pp 227-245.

12. Gurevich, A.; Saveliev, V.; Vyahhi, N.; Tesler, G., QUAST: quality assessment tool for genome assemblies. Bioinformatics 2013, 29 (8), 1072-1075.

13. CLSI, Methods for Dilution Antimicrobial Susceptibility Tests for Bacteria that Grow Aerobically; Approved Standard - Ninth Edition. Clinical and Laboratory Standards Institute: Wayne, PA, 2012; Vol. CLSI document M07-A9.

14. Polikanov, Y. S.; Starosta, A. L.; Juette, M. F.; Altman, R. B.; Terry, D. S.; Lu, W.; Burnett, B. J.; Dinos, G.; Reynolds, K. A.; Blanchard, S. C.; Steitz, T. A.; Wilson, D. N., Distinct tRNA Accommodation Intermediates Observed on the Ribosome with the Antibiotics Hygromycin A and A201A. Mol Cell 2015, $58(5), 832-44$.

15. Starosta, A. L.; Karpenko, V. V.; Shishkina, A. V.; Mikolajka, A.; Sumbatyan, N. V.; Schluenzen, F.; Korshunova, G. A.; Bogdanov, A. A.; Wilson, D. N., Interplay between the ribosomal tunnel, nascent chain, and macrolides influences drug inhibition. Chem Biol 2010, 17 (5), 504-14.

16. Zinshteyn, B.; Chan, D.; England, W.; Feng, C.; Green, R.; Spitale, R. C., Assaying RNA structure with LASER-Seq. Nucleic Acids Res 2019, 47 (1), 43-55.

17. McClary, B.; Zinshteyn, B.; Meyer, M.; Jouanneau, M.; Pellegrino, S.; Yusupova, G.; Schuller, A.; Reyes, J. C. P.; Lu, J.; Guo, Z.; Ayinde, S.; Luo, C.; Dang, Y.; Romo, D.; Yusupov, M.; Green, R.; Liu, J. O., Inhibition of Eukaryotic Translation by the Antitumor Natural Product Agelastatin A. Cell Chem Biol 2017, 24 (5), 605-613 e5. 
18. Siegfried, N. A.; Busan, S.; Rice, G. M.; Nelson, J. A.; Weeks, K. M., RNA motif discovery by SHAPE and mutational profiling (SHAPE-MaP). Nat Methods 2014, 11 (9), 959-65.

19. Kurylo, C. M.; Alexander, N.; Dass, R. A.; Parks, M. M.; Altman, R. A.; Vincent, C. T.; Mason, C. E.; Blanchard, S. C., Genome Sequence and Analysis of Escherichia coli MRE600, a Colicinogenic, Nonmotile Strain that Lacks RNase I and the Type I Methyltransferase, EcoKI. Genome Biol Evol 2016, 8 (3), 742-52. 20. Hansen, J. L.; Ippolito, J. A.; Ban, N.; Nissen, P.; Moore, P. B.; Steitz, T. A., The structures of four macrolide antibiotics bound to the large ribosomal subunit. Mol Cell 2002, 10 (1), 117-28.

21. Dunkle, J. A.; Xiong, L.; Mankin, A. S.; Cate, J. H., Structures of the Escherichia coli ribosome with antibiotics bound near the peptidyl transferase center explain spectra of drug action. Proc Natl Acad Sci U S A 2010, 107 (40), 17152-7.

22. Arenz, S.; Juette, M. F.; Graf, M.; Nguyen, F.; Huter, P.; Polikanov, Y. S.; Blanchard, S. C.; Wilson, D. N., Structures of the orthosomycin antibiotics avilamycin and evernimicin in complex with the bacterial 70S ribosome. Proc Natl Acad Sci U S A 2016, 113 (27), 7527-32.

23. Emsley, P.; Cowtan, K., Coot: model-building tools for molecular graphics. Acta Crystallogr D Biol Crystallogr 2004, 60 (Pt 12 Pt 1), 2126-32.

24. Seefeldt, A. C.; Graf, M.; Perebaskine, N.; Nguyen, F.; Arenz, S.; Mardirossian, M.; Scocchi, M.; Wilson, D. N.; Innis, C. A., Structure of the mammalian antimicrobial peptide Bac7(1-16) bound within the exit tunnel of a bacterial ribosome. Nucleic Acids Res 2016, 44 (5), 2429-38.

25. Seefeldt, A. C.; Nguyen, F.; Antunes, S.; Perebaskine, N.; Graf, M.; Arenz, S.; Inampudi, K. K.; Douat, C.; Guichard, G.; Wilson, D. N.; Innis, C. A., The proline-rich antimicrobial peptide Onc112 inhibits translation by blocking and destabilizing the initiation complex. Nat Struct Mol Biol 2015, 22 (6), 470-5.

26. Starosta, A. L.; Lassak, J.; Peil, L.; Atkinson, G. C.; Virumae, K.; Tenson, T.; Remme, J.; Jung, K.; Wilson, D. N., Translational stalling at polyproline stretches is modulated by the sequence context upstream of the stall site. Nucleic Acids Res 2014, 42 (16), 10711-9.

27. Orelle, C.; Carlson, S.; Kaushal, B.; Almutairi, M. M.; Liu, H.; Ochabowicz, A.; Quan, S.; Pham, V. C.; Squires, C. L.; Murphy, B. T.; Mankin, A. S., Tools for characterizing bacterial protein synthesis inhibitors. Antimicrob Agents Chemother 2013, 57 (12), 5994-6004.

28. Zaporojets, D.; French, S.; Squires, C. L., Products transcribed from rearranged rrn genes of Escherichia coli can assemble to form functional ribosomes. J Bacteriol 2003, 185 (23), 6921-7.

29. Kim, T. W.; Keum, J. W.; Oh, I. S.; Choi, C. Y.; Park, C. G.; Kim, D. M., Simple procedures for the construction of a robust and cost-effective cell-free protein synthesis system. J Biotechnol 2006, 126 (4), 554-61.

30. Sohmen, D.; Chiba, S.; Shimokawa-Chiba, N.; Innis, C. A.; Berninghausen, O.; Beckmann, R.; Ito, K.; Wilson, D. N., Structure of the Bacillus subtilis $70 \mathrm{~S}$ ribosome reveals the basis for species-specific stalling. Nat Commun 2015, 6, 6941.

31. Mardirossian, M.; Barriere, Q.; Timchenko, T.; Muller, C.; Pacor, S.; Mergaert, P.; Scocchi, M.; Wilson, D. N., Fragments of the Nonlytic Proline-Rich Antimicrobial Peptide Bac5 Kill Escherichia coli Cells by Inhibiting Protein Synthesis. Antimicrob Agents Chemother 2018, 62 (8).

32. Mardirossian, M.; Sola, R.; Beckert, B.; Collis, D. W. P.; Di Stasi, A.; Armas, F.; Hilpert, K.; Wilson, D. N.; Scocchi, M., Proline-Rich Peptides with Improved Antimicrobial Activity against E. coli, K. pneumoniae, and A. baumannii. ChemMedChem 2019, 14 (24), 2025-2033.

33. Datsenko, K. A.; Wanner, B. L., One-step inactivation of chromosomal genes in Escherichia coli K12 using PCR products. Proceedings of the National Academy of Sciences of the United States of America 2000, $97(12), 6640-5$.

34. MacNeil, D. J.; Gewain, K. M.; Ruby, C. L.; Dezeny, G.; Gibbons, P. H.; MacNeil, T., Analysis of Streptomyces avermitilis genes required for avermectin biosynthesis utilizing a novel integration vector. Gene 1992, 111 (1), 61-8. 
35. Bierman, M.; Logan, R.; Obrien, K.; Seno, E. T.; Rao, R. N.; Schoner, B. E., Plasmid Cloning Vectors for the Conjugal Transfer of DNA from Escherichia-Coli to Streptomyces Spp. Gene 1992, 116 (1), 43-49. 